KYOTO UNIVERSITY

HEMATOLOGICAL INVESTIGATION OF THE ATOMIC BOMB SUFFERERS IN HIROSHIMA AND NAGASAKI CITY

By

Takehiko Kikuchi

Gyoichi Wakisaka

1952

Kyoto University

Japan

UNITED STATES ATOMIC ENERGY COMMISSION Technical Information Extension, Oak Ridge, Tennessee 


\section{LEG A L NOTICE}

Neither the United States, nor the Commission, nor any person acting on behalf of the Commission:

A. Makes any warranty or representation, express or implied, with respect to the accuracy, completeness, or usefulness of the information contained in this report, or that the use of any information, apparatus, method, or process disclosed in this report may not infringe privately owned rights; or

B. Assumes any liabilities with respect to the use of, or for damages resulting from the use of any information, apparatus, method, or process disclosed in this report.

As used in the above, "person acting on behalf of the Commission" includes any employee or contractor of the Commission to the extent that such empioyee or contractor prepares, handles or distributes, or provides access to, any information pursuant to his employment or contract with the Commission.

This report has been reproduced directly from the best available copy.

Printed in USA. Price $\$ 1.00$. Available from the Office of Technical Services, Department of Commerce, Washington 25, D. C. 


\section{DISCLAIMER}

This report was prepared as an account of work sponsored by an agency of the United States Government. Neither the United States Government nor any agency Thereof, nor any of their employees, makes any warranty, express or implied, or assumes any legal liability or responsibility for the accuracy, completeness, or usefulness of any information, apparatus, product, or process disclosed, or represents that its use would not infringe privately owned rights. Reference herein to any specific commercial product, process, or service by trade name, trademark, manufacturer, or otherwise does not necessarily constitute or imply its endorsement, recommendation, or favoring by the United States Government or any agency thereof. The views and opinions of authors expressed herein do not necessarily state or reflect those of the United States Government or any agency thereof. 


\section{DISCLAIMER}

Portions of this document may be illegible in electronic image products. Images are produced from the best available original document. 
NP-6435

\title{
Hematological Investigation of the Atomic Bomb \\ Sufferers in Hiroshima and Nagasaki City
}

\author{
By \\ Takehiko KIKUCHI and Gyoichi WAKISAKA \\ (From the Second Medical Clinic, Faculty of Medicine, Kyoto University
}

\author{
Reprinted from the Acta Scholae Medicinalis \\ Universitatis in KIOTO \\ Vol. 30, Fasc. 2, 1952.
}




\section{Hematological investigation of the atomic bomb sufferers in Hiroshima and Nagasaki City.* \\ By}

Takehiko KIKUCHI and Gyoichi WaKISAKA

From the Serond Medical Clinic, Faculty of Medicine, Kyoto University

(Director : Prof. Takehiko KIxuchI, M. D.)

\section{Introducţion}

The clinical picture of the atomic bomb injuries has been reported in detail by $\mathrm{KIKUCHI}^{, 1)}$ one of the authors of this paper, at the Twelfth Congress of the Japanese Association of Medical Science, which was held in April, 1947. Furthermore atcmic bomb injuries have been reviewed by TsuzUKI,") SASSA, ${ }^{3)}$ NAKAIZUMI,") KinOSHITA and MIYAKE ${ }^{5)}$ in the "Report on the Atomic Bomb Disasters" recently published by the Special Research Committee on the Atomic Bomb Disasters aided by the Scientific Research Council of the Japanese Educational Ministry.

In this paper we are going to describe the clinical picture of the acute and subacute radiation injuries caused by the atomic bomb from the hematological point of view, based upon the investigation of 1998 cases of atomic bomb sufferers observed by us (Table 1) ${ }^{\text {s), }}$ 10), 11, 401, 41, 43), 44) and 2850 case records presented to us from the authorities of many universities and hospitals at our request in 1947.

This report will also cover the sequelae of the atomic bomb injuries one and two years after the bombing.

\section{Outlines of clinical picture}

The influence of the atomic bomb on the human body may be divided into

* A collaborative clinical investigation by the following members of the Second Medical Clinic, Faculty of Medicine, Kyoty University

Teiji SasakI, Tadatsugu Orubo, Takeshi Setruda, Masaichi Furase, Shigenori Anzai, Tadamasa Yokoyama, Kiyoshi Muruta, Tatsujiro Oga, Tatsuo Hiraora, Shinsei Nishivama, Jusaburo Hamanishi, Bunji UBA, Motozo NreHikawa, Shigeyuki ItoI, Tsuyoshi UmEDA, Junichi OKAmoto, Okiatsu HAMA, Terumasa Murakami, Tsuneo Sawada, Shinya Note, Jiro Tanaka, Hiroshi Yamada, Kiyoharu Mrki, Tomio Yoda, Ryuichi Ishroami, Yoshimichi Yamasobs, Teiji Nasu, Seiichiro Akiyama, Yasuharu Tejima, Hikaru Ishigam, Yaichiro ShIorawa, Mitsuo TakedA, and Susumu Fujimura. 
Table 1 Cases examined

\begin{tabular}{l|l|r|r}
\hline \multicolumn{1}{c|}{ City } & \multicolumn{1}{|c|}{ Patients } & $\begin{array}{l}\text { Number } \\
\text { of cases }\end{array}$ & Period of observation \\
\hline \multirow{3}{*}{ Hiroshima } & In-patients of the Ono Army Hospital & 76 & Sep. 5 - Sep.17, 1945 \\
\cline { 2 - 5 } & Out-patients of the Ono Army Hospital & 140 & Sep. 5 - Sep. 17, 1945 \\
\cline { 2 - 5 } & Out -patients of the Ushida Clinic & 645 & Sep.10 - Sep.17, 1945 \\
\hline Nagasaki & In-patients of the Mitsubishi Hospital & 26 & Nov. 1 - Nov.15, 1945 \\
\hline Hiroshima & Out-patients of circulating clinics & 523 & Aug.19 - Sep.10, 1946 \\
\hline \multirow{2}{*}{ Nagasaki } & Out-patients of circulating clinics & 172 & Nov.30 - Dec. 6, 1946 \\
\cline { 2 - 5 } & Out -patients in Nishiyama area & 173 & Feb.15 - Feb. 20, 1947 \\
\hline Hiroshima & Out -patients of circulating clinics & 243 & Oct. 10 - Oct.19, 1947 \\
\hline Total & & 1998 & \\
\hline
\end{tabular}

(1) mechanical effects

(2) effects due to heat and other rays

(3) effects due to ionizing radiations.

Of these effects, the radiation effects are most characteristic of the atomic bomb injuries. Therefore we will discuss chiefly the atomic bomb injuries caused by the radiation effects, namely, atomic bomb radiation sickness, or in short, "radiation sickness". The symptoms of radiation sickness depend upon the doses of radiation received by individuals, which vary according to the distance from the bombing center and the efficiency of the shelter under which the individuals were placed. The closer to the bombing center the individuals were situated at the time of bombing, the higher the incidence of radiation sickness. Typical cases of radiation sickness were found chiefly within $2 \mathrm{~km}$ from the bombing center. There were also found, however, a few cases of radiation sickness even at a distance of 2 to $3 \mathrm{~km}$ from the bombing center.

\section{Changes of peripheral blood}

As the clinical picture of radiation sickness varies according to the stage of the disease, we will divide it into 4 stages given below:

1) The 1 st stage From immediately after the bombing to the end of the 2. week - Acute symptoms

2) The 2 nd stage From the 3. to 8 , week-Subacute symptoms Complications

3) The $3 \mathrm{rd}$ stage From the 3. to 4. month-Recovery stage 
4) The $4^{\text {th }}$ stage From the 5. month and on - Sequelae

Chronic symptoms

1) The Ist stage. Most of the sufferers complained of early symptoms such as general malaise, lassitude, nausea, vomiting and diarrhea. Although these complaints were more remarkable in those who have developed radiation sickness afterwards, they were also seen in many sufferers who did not show any particular symptom of radiation sickness. Those who were bombed very near the bombing center were for the most part killed immediately or died within the day of the bombing. Among the remainder there were also many cases which died from general emaciation within two or three days after the bombing in spite of slight burns or mechanical injuries. These patients are regarded to have suffered from the most severe radiation injuries. The details of the clinical and laboratory findings of these patients, however, are not available. Other patients complained of fever from $38^{\prime}$ to $39^{\circ} \mathrm{C}$ beginning on the 3. or 4. day after the bombing accompanied by obstinate, sometimes bloody or mucous diarrhea, vomiting, hematemesis, hemoptysis, hematuria, etc., and died about ten days after the bombing. These patients are also regarded to have suffered from very severe radiation injuries. The details of the clinical and laboratory findings in these cases are also unknown. According to the report of the Kure Naval Station, ${ }^{6)}$ however, these patients already showed remarkable leukopenia within a week after the bombing. As given in Table 2, 7 cases out of 10 showed marked leukopenia ranging between 150 and 400 per $\mathrm{cmm}$. In cases with marked leukopenia, the lymphocytes were reduced remarkably both in percentage and in absolute number. The neutrophils were also reduced remarkably in absolute number. In percentage, however, they showed relative neutrophilia, because the decrease of the lymphocytes was more remarkable than that of the neutrophils. Consequently the ratio of the neutrophils to the lymphocytes $\left(\frac{N}{L}\right)$ was higher than normal (1. 1-2.4), ranging between 3.9 and 10.8. The nuclear count of the neutrophils showed a marked shift to the left. Metamyelocytes were seen in most cases. The percentage of the eosinophils and monocytes were within the normal range even in the cases with marked leukopenia, although they were reduced in absolute number. The erythrocyte count and hemoglobin content were remarkably reduced in some cases. The decrease of the erythrocyte count and hemoglobin content, however, was generally not so remarkable as that of the leukocyte count. The color index was lowered in many 
Table 2 Blood picture within 1 week after the bombing (Kure Naval Station)6)

\begin{tabular}{|c|c|c|c|c|c|c|c|c|c|c|c|c|c|c|c|}
\hline \multirow{3}{*}{ Name } & \multirow{3}{*}{$\begin{array}{c}\text { Erythro- } \\
\text { cyte } \\
(\times 10000)\end{array}$} & \multirow{3}{*}{$\begin{array}{c}\text { Hemo- } \\
\text { globin } \\
\%\end{array}$} & \multirow{3}{*}{$\begin{array}{l}\text { Color } \\
\text { index }\end{array}$} & \multirow{3}{*}{$\begin{array}{c}\text { Leuko- } \\
\text { cyte }\end{array}$} & \multicolumn{10}{|c|}{ Diffe, ential count } & \multirow{3}{*}{$\begin{array}{l}\text { Out. } \\
\text { come }\end{array}$} \\
\hline & & & & & \multirow{2}{*}{$\begin{array}{l}\text { Baso- } \\
\text { phils }\end{array}$} & \multirow{2}{*}{$\begin{array}{l}\text { Eosino- } \\
\text { phils }\end{array}$} & \multicolumn{5}{|c|}{ Neutrophils } & \multirow{2}{*}{$\begin{array}{c}\text { Lympho- } \\
\text { cyte }\end{array}$} & \multirow{2}{*}{$\begin{array}{l}\text { Mono } \\
\text { cyte }\end{array}$} & \multirow{2}{*}{$\begin{array}{l}\text { Neutrophils } \\
\text { Lymphocytes } \\
\end{array}$} & \\
\hline & & & & & & & $\begin{array}{c}\text { Myelo- } \\
\text { cyte }\end{array}$ & $\begin{array}{l}\text { Meta- } \\
\text { myelocyte }\end{array}$ & $\begin{array}{l}\text { Stab } \\
\text { cells }\end{array}$ & $\begin{array}{c}\begin{array}{c}\text { Polymorpho- } \\
\text { nuclears }\end{array} \\
\end{array}$ & Total & & & & \\
\hline O. & 375 & 40 & 0.53 & 250 & 0 & 2 & 0 & 4 & 26 & 56 & $\begin{array}{c}86 \\
(215) \\
\end{array}$ & $\begin{array}{r}8 \\
(20) \\
\end{array}$ & 4 & 10.8 & \\
\hline F. & 410 & 42 & 0.51 & 400 & $\mathbf{0}$ & 1 & 0 & 11 & 13 & 53 & $\begin{array}{c}77 \\
(308)\end{array}$ & $\begin{array}{c}20 \\
(80)\end{array}$ & 2 & 3.9 & Fatal \\
\hline N. & 420 & 50 & 0.59 & 150 & $\mathbf{0}$ & 2 & 0 & 9 & 8 & 66 & $\begin{array}{c}83 \\
(125) \\
\end{array}$ & $\begin{array}{c}13 \\
(20) \\
\end{array}$ & 2 & 6.4 & Fatal \\
\hline K. & 420 & 45 & 0.53 & 400 & 1 & 0 & 0 & 9 & 12 & 62 & $\begin{array}{c}83 \\
(332) \\
\end{array}$ & $\begin{array}{c}14 \\
(56) \\
\end{array}$ & 2 & 5.9 & Fatal \\
\hline F. & 265 & 32 & 0.60 & 400 & & & & & & & & & & & Fatal \\
\hline $\mathbf{Y}$. & 184 & 23 & 0.62 & 340 & & & & & & & & & & & Fatal \\
\hline o. & 528 & 43 & 0.41 & 150 & 3 & 4 & 0 & 9 & 30 & 34 & $\begin{array}{c}73 \\
(110) \\
\end{array}$ & $\begin{array}{c}17 \\
(26) \\
\end{array}$ & 3 & 4.3 & Fatal \\
\hline $\mathbf{K}$. & 300 & 49 & 0.81 & 4000 & 2 & 3 & 0 & 1 & 8 & 45 & $\begin{array}{c}54 \\
(2160)\end{array}$ & $\begin{array}{c}36 \\
(1440)\end{array}$ & 5 & 1.5 & \\
\hline K. & 405 & 95 & 1.17 & 3080 & 1 & 4 & 0 & 0 & 10 & 48 & $\begin{array}{c}58 \\
(1663) \\
\end{array}$ & $\begin{array}{c}34 \\
(1047) \\
\end{array}$ & 3 & 1.7 & \\
\hline s. & 330 & 65 & 0.98 & 3800 & 0 & 5 & 0 & 0 & 24 & 44 & $\begin{array}{c}68 \\
(2584)\end{array}$ & $\begin{array}{c}22 \\
(836)\end{array}$ & 5 & 3.1 & \\
\hline Normal & $450-500$ & $90-100$ & 1.00 & $\begin{array}{c}6000 \\
-8000 \\
\end{array}$ & $0-1$ & $1-5$ & 0 & 0 & $3-6$ & $45-55$ & $\mid \begin{array}{c}48-61 \\
(2880 \\
-4880)\end{array}$ & $\begin{array}{c}25-45 \\
(1500 \\
-3600)\end{array}$ & $4-7$ & $1.1-2.4$ & \\
\hline
\end{tabular}

( ); Absolute number 
Fig. 1 Leukocyte count in the first week after the bombing

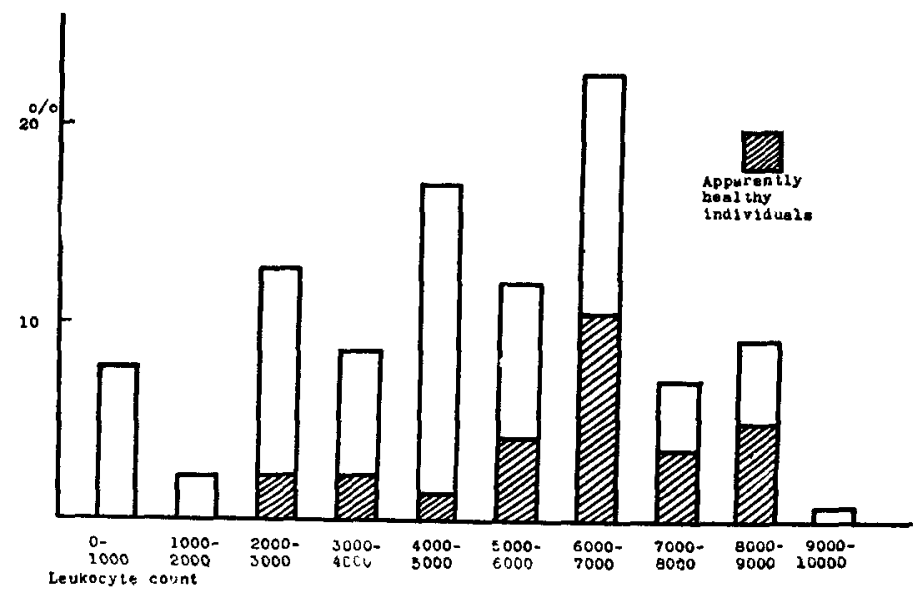

cases.

Fig. 1 shows the leukocyte counts in the first week after the bombing examined in 141 cases $^{6)}$ ), which were exposed to the atomic bomb within $1.5 \mathrm{~km}$ from the bombing center. In $48.3 \%$ of all cases examined, the leukocyte count was less than 5000 per $\mathrm{cmm}$. There were not a few cases with leukopenia, which at that time had no subjective symptom and could continue military service as healthy individuals. Many of these apparently healthy individuals, however, developed a typical radiation sickness three or four weeks after the bombing.

2) The 2 nd and 3 rd stage.

Typical radiation sickness began as early as from five to six days, mostly about two weeks after the bombing with epilation, followed by fever, bleeding in the skin and mucous membrane, gingivitis, pharyngitis and diarrhea. Among these symptoms, fever, hemorrhagic tendencies, gingivitis and pharyngitis ran parallel with the hematological changes such as leukopenia and thrombocytopenia both in their severity and time of onset, indicating that there is a close relation between them.

The changes of the blood picture in this stage were examined in detail. We will explain the changes of the peripheral blood picture, dividing the cases into follwing 4 groups.

Group

I) Fatal cases
Symptoms

High fever, marked epilation, prominent hemorrhagic tendencies, necrotic gingivitis and tonsillitis, diarrhea. 
II) Severe cases High fever, marked epilation, hemorrhagic tendencies, gingivitis and pharyngitis.

III) Middle cases Moderate fever, slight hemorrhagic tendencies, slight gingivitis and pharyngitis.

IV Slight cases Only one or two of the above mentioned symptoms.

1) Fatal cases (Fig. 2). The erythrocyte count and hemoglobin content were reduced considerably, becoming more and more remarkable with the lapse of time. The color index was higher than 1.0, and it showed especially a tendency to rise at the terminal stage of the disease. The reticulocyte count was decreased. The leukocyte count was reduced remarkably, showing the average value of 1100 per cmm three weeks after the bombing. There were not a few cases with the leukocyte caunt less than 500 per $\mathrm{cmm}$.

The decrease of the neutrophils was especially pronounced. They were reduced remarkably not only in percentage but also in absolute number. The absolute number of the neutrophils was less than that of the lymphocytes. The lymphocytes were also reduced in absolute number. In percentage, however, they were increased because the decrease of the neutrophils outbalanced that of the lymphocytes. Consequently the ratio of the neutrophils to the lymphocytes $\left(\frac{N}{1}\right)$ was remarkably lower than normal. The eosinophils were reduced or disappeared in most cases. Usually the basophils were not found. The monocytes were also decreared. Plasma cells appeared in many cases.

The leukocyte count showed a tendency to decrease progressively in most cases, although there were some cases, in which the leukocyte count showed a slight increase aiter reaching its lowest level. The platelets were also remarkably decreased, the count being less than 50,000 per $\mathrm{cmm}$ in most cases.

2 ) Severe cases (Fig. 3).

The erythrocyte count was markedly reduced, showing the average value of 2.825 million per $\mathrm{cmm}$ in the 4 . week after the bombing. It decreased more and more until the 8 . week, and then began to recover. In the 15 . to 18 . week, however, it was still below normal value, showing the average value of 4.1 million per $\mathrm{cmm}$. The hemoglobin content was also decreased remarkably, averaging $59 \%$ (Sahli) in the 4 . week aiter the bombing. It decreased further until the 6. week, and thereafter it began to increase gradually. In the 15 . to 18 . week, however, it was not restored to normal, 
Fig. 2 Peripheral blood picture (Fatal cases)

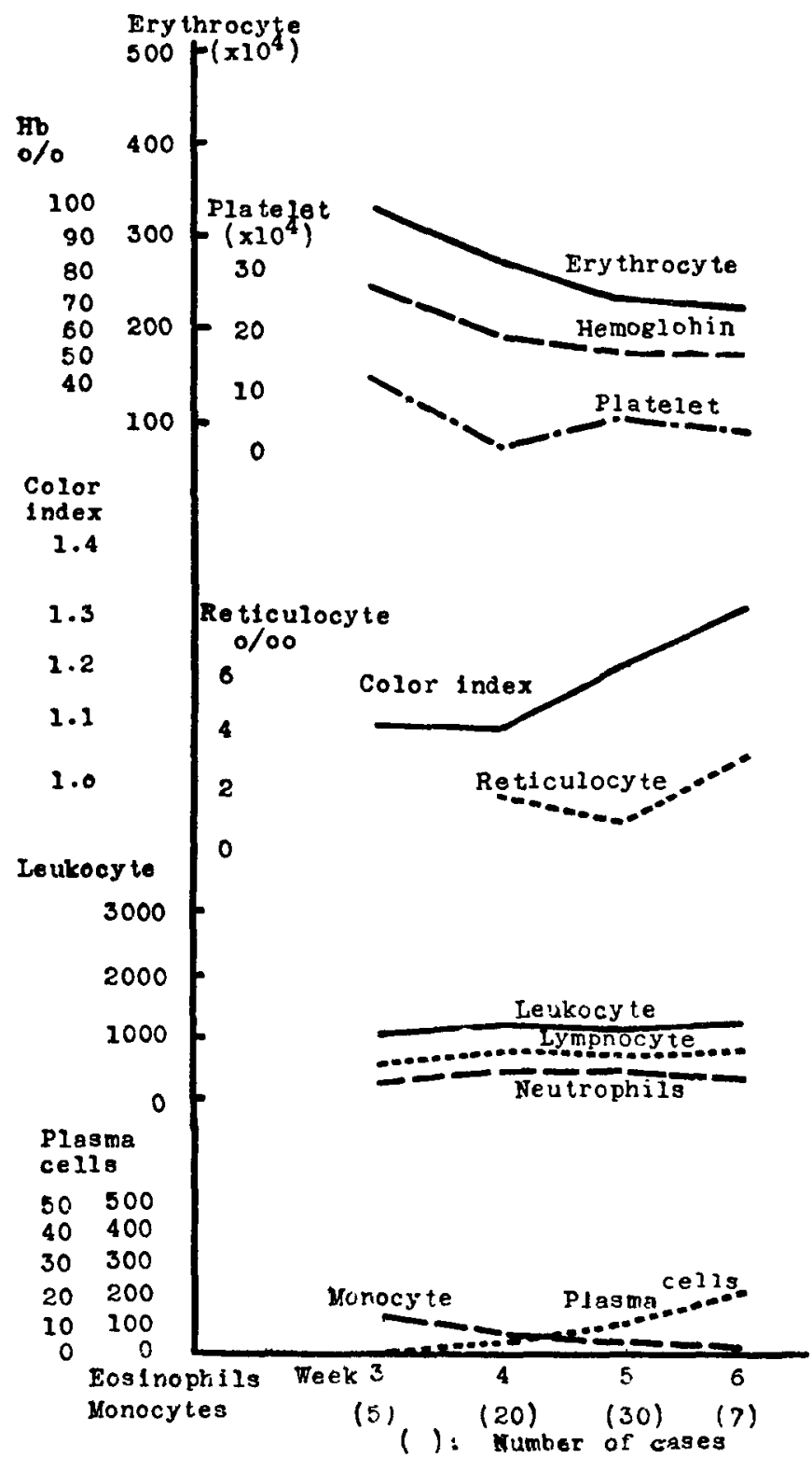

showing the average value of $86 \%$ (Sahli). The color index had a tendency to rise, ranging between 1.1 and 1.3, during the stage when the erythrocyte count was decreasing. It returend to 1.0 as the erythrocyte count approached normal. The reticulocyte count 
Fig. 3 Peripheral blood picture (Severe cases)

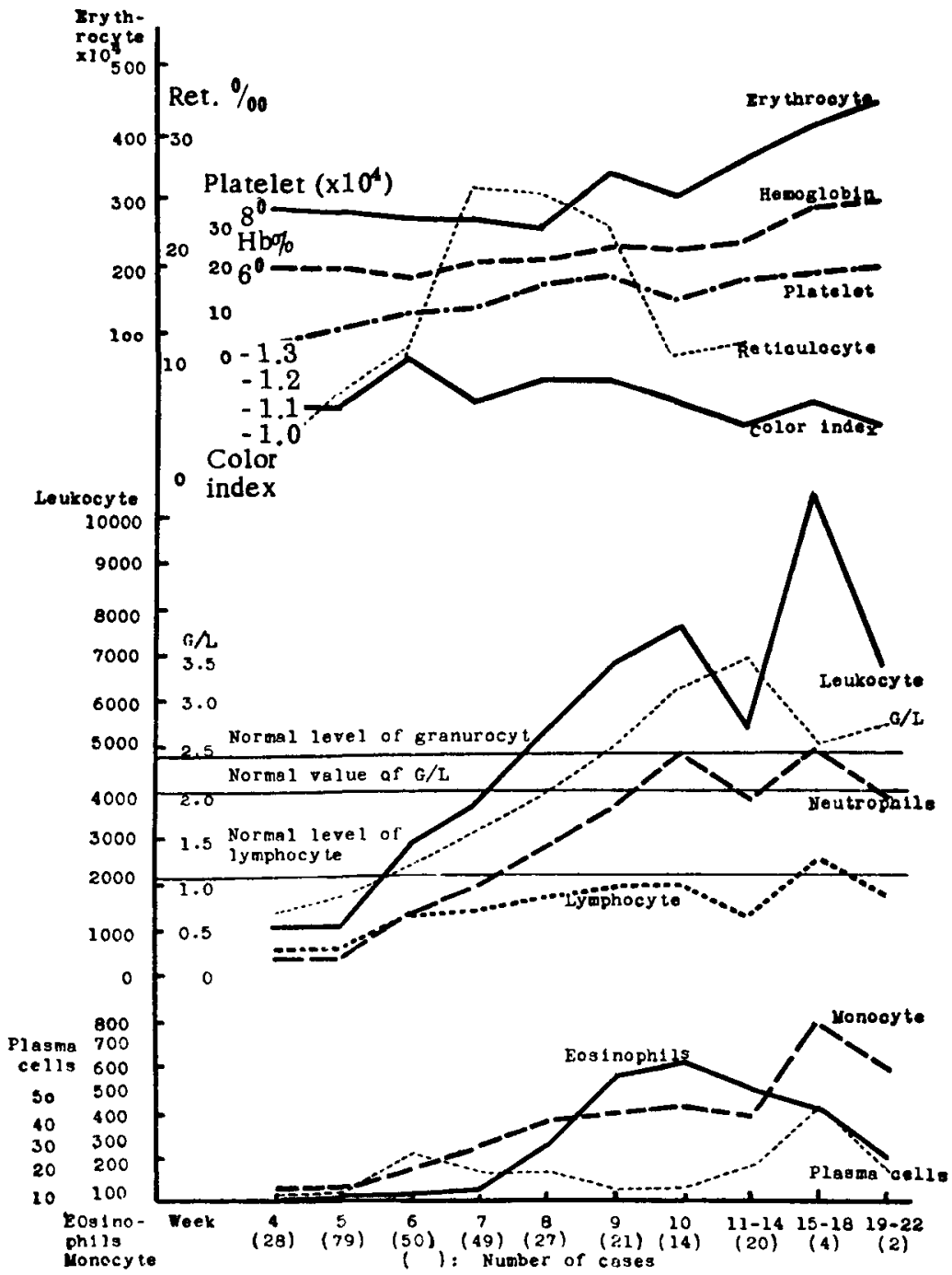

was reduced in the 4 . week, averaging $1.3 \%$. After the 5 . week it began to increase, reaching the highest level of $25.2 \%$ in the 7 . week, and then it began to decrease with the increase of the erythrocyte count, showing the average value of $10 \%$ in the 10 . week.

The platelet count was markedly reduced in the 4 . week, being 32,000 per $\mathrm{cmm}$ in average. In the 5 . week it recovered to 67,000 per $\mathrm{cmm}$, and thereafter, it increased gradually. In the 11 . to 14 . week, however, it was still below normal level, showing the average 
value of 168,000 per $\mathrm{cmm}$.

The leukocyte count was remarkably reduced in the 4. week, being 1015 per $\mathrm{cmm}$ in average. In the 5 . week, there was no sign of recovery in the leukocyte count. After the 6. week, however, the leukocyte count began to increase rapidly, and restored to normal in the 10. week, showing the average value of 7578 per $\mathrm{cmm}$. In the 15. to 18. week it increased temporarily above normal (10425 per $\mathrm{cmm}$ in average) and returned to normal in the 19. to 22 . week. As for the differential count, the neutrophils were markedly reduced in the 4 . week. Its count was 304 per $\mathrm{cmm}$ in average, being less than that of the lymphocytes. In the 6 . week, however, the count of the eosinophils showed the same number as that of the lymphocytes, and thereafter it increased in proportion to the increase of the total leukocyte count, reaching normal level in the 9. week. The lymphocytes were reduced to less than a half of the normal count in the 4. to 5 . week, and thereafter they began to increase. The rate of their increase, however, was slow in most cases. The average count of the lymyhocytes did not yet recover to the normal value $(2100$ per $\mathrm{cmm})$ in the 10 . week. It recovered to normal for the first time in the 15. to 18. week. When the lymphocytes were on the way to recovery, there was an increase of the immature lymphocytes with an increased number of mitochondria.9)

The easinophils were decreased or disappeared in the 4 . to 7 . week. After the 8 . week they began to increase, and after a temporary increase above normal in the 9. to 10 . week, they returned to normal again. The basophils were usually not found. The monocytes were reduced in the 4 . to 5 . week. Thereafter they began to increase gradually, showing a tendency to increase above normal in the 15. to 18. week. The plasma cells were often increased in the 5. to 15. week, and thereafter they decreased gradually.

Fig. 3 shows the recovery rate of the granulocytes and lymphocytes in severe cases. At the acme of the disease, the ratio of the granulocytes to lymphocytes $\left(\frac{(j}{L}\right)$ was markedly lowered below normal. At the recovery stage, however, the increase of the granulocytes was rapider than that of the lymphocytes. Consequently the ratio of the granulocytes to lymphocytes returned relatively rapidly to normal, or temporarily even increased above normal.

The changes of the blood picture in middle and slight cases were the same in principle as in severe cases. The degree of the changes, however, was slighter, and the lowest level of the leukocyte count seemed to appear later in slight cases (Fig. 4). 
Fig. 4 Changes of mean leukocyte count

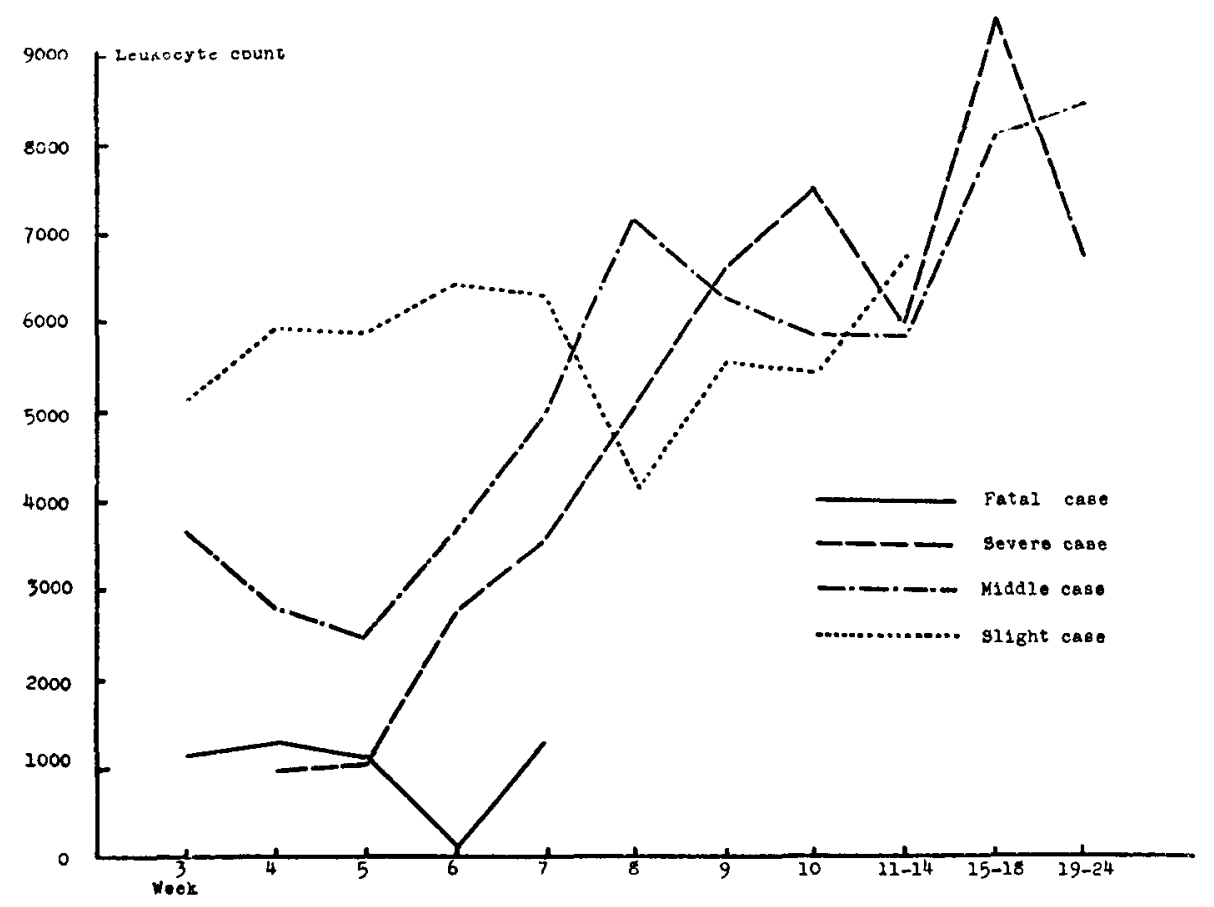

Nuclear shift of the neutrophils (Fig. 5).

During the marked leukopenia in the 4 . to 6 . week, there was a remarkable shift to the left in the nuclear count of the neutrophils. With the recovery of the total leukocyte count, however, it apprcached gradually to the normal value. The immature leukocytes, younger than myelocytes, were rare even at the stage with a marked shift to the left of the nuclear count. It was reported that the immature leukocytes such as promyelocytes and myeloblasts appeared in a lew cases. In our investigation, how ever, we could not observe such cases.

Morphological and functional changes of leukocytes (Fig. 6). During the acme of leukopenia, there were various degenerative changes of leukocytes such as vacuolation, toxic granulation, pyknosis of nuclei, pcor staining, swelling of nuclei and the like. The neutrophils appeared to become much larger than usual, and the mean diameter of the neutrophils was increased in severe cases.

The phagocytic activity of the neutrophils, tested with Indian ink forty-six to seventy-six days after the bombing, was lowered not only in the cases with Jeukopenia, but also in the cases with 
Fig. 5 Neuclear shift of neutrophils

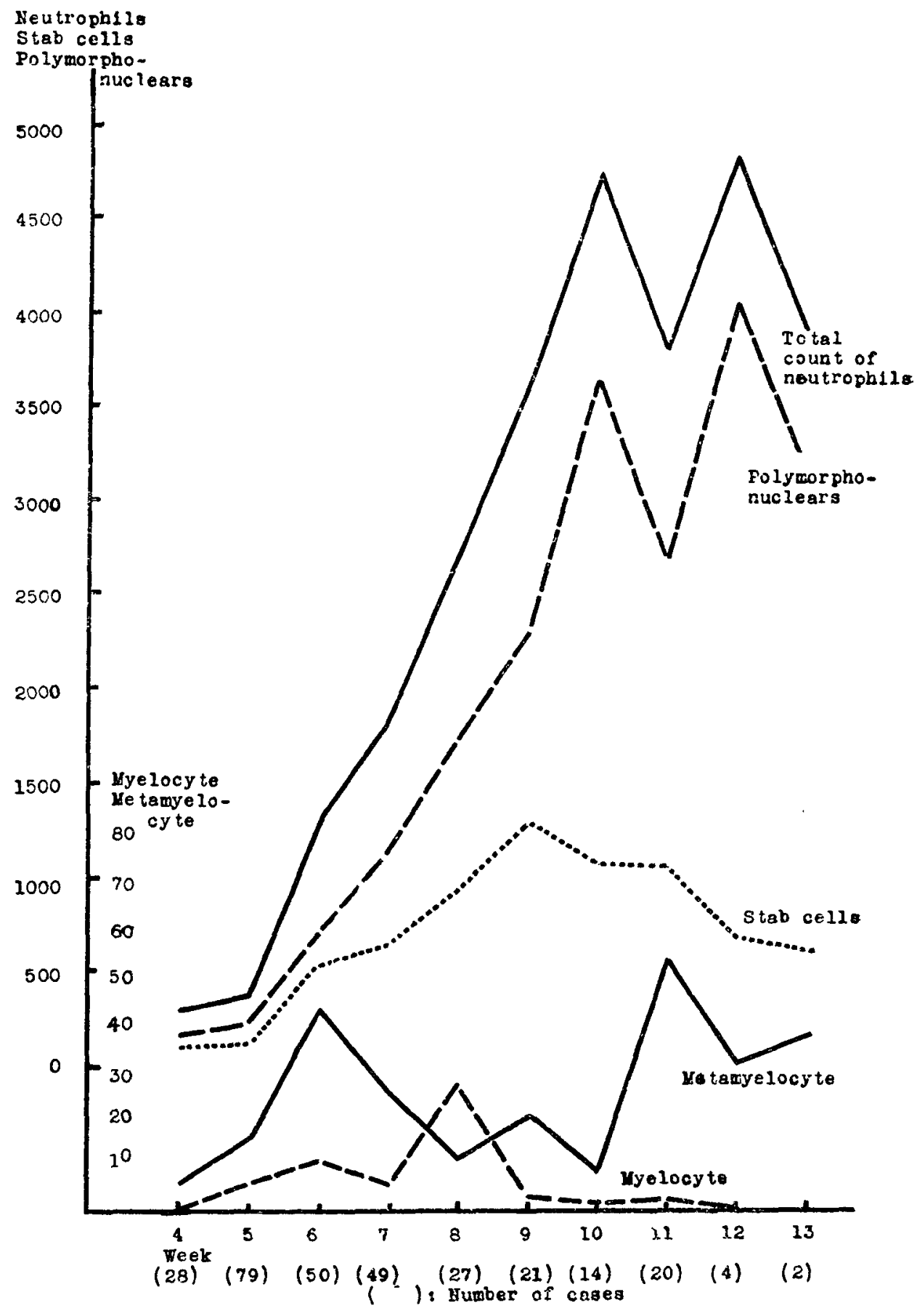




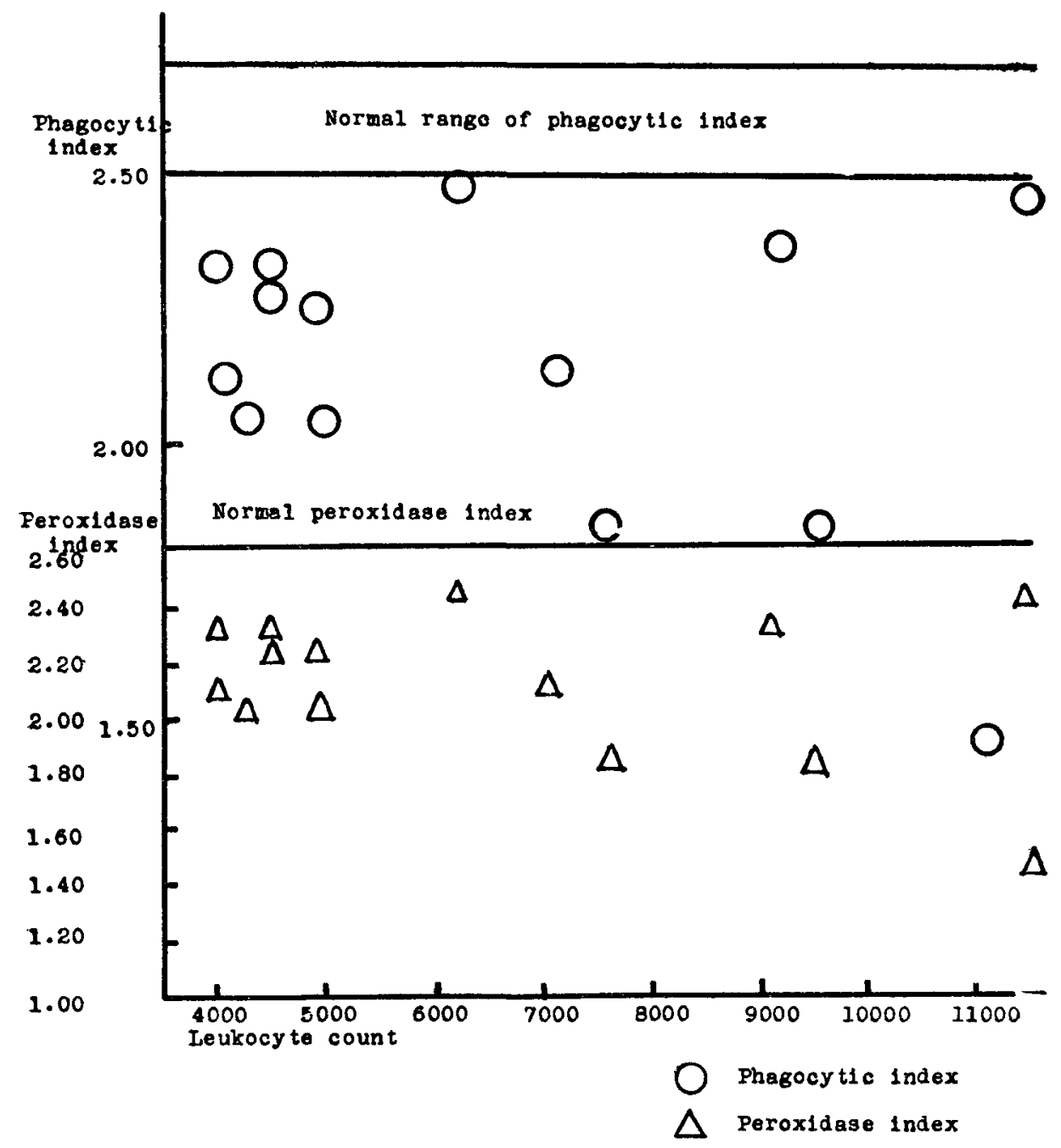

normal or increased leukocyte count. This result may be considered to show that the functions of leukocytes were not restored to normal even after the leukocyte count had returned to normal.9) The peroxidase reaction of the neutrophils was also decreased.9)

Morphological changes of erythrocytes (Fig. 7).

In the 3 . to 6 . week after the bombing, the more severe the cases were, the more remarkable was the anisocytosis. It was found in $62 \%$ to $40 \%$ of fatal cases, and in $44 \%$ to $46 \%$ of severe cases. With the recovery of anemia, however, the anisocytosis became less prominent. Poikilocytosis was not pronounced. In severe cases, it 


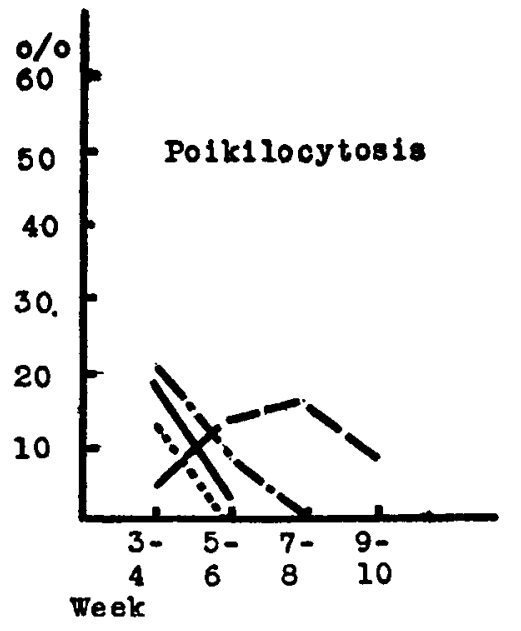

Fig. 7 Morphological changes of erythrocyte
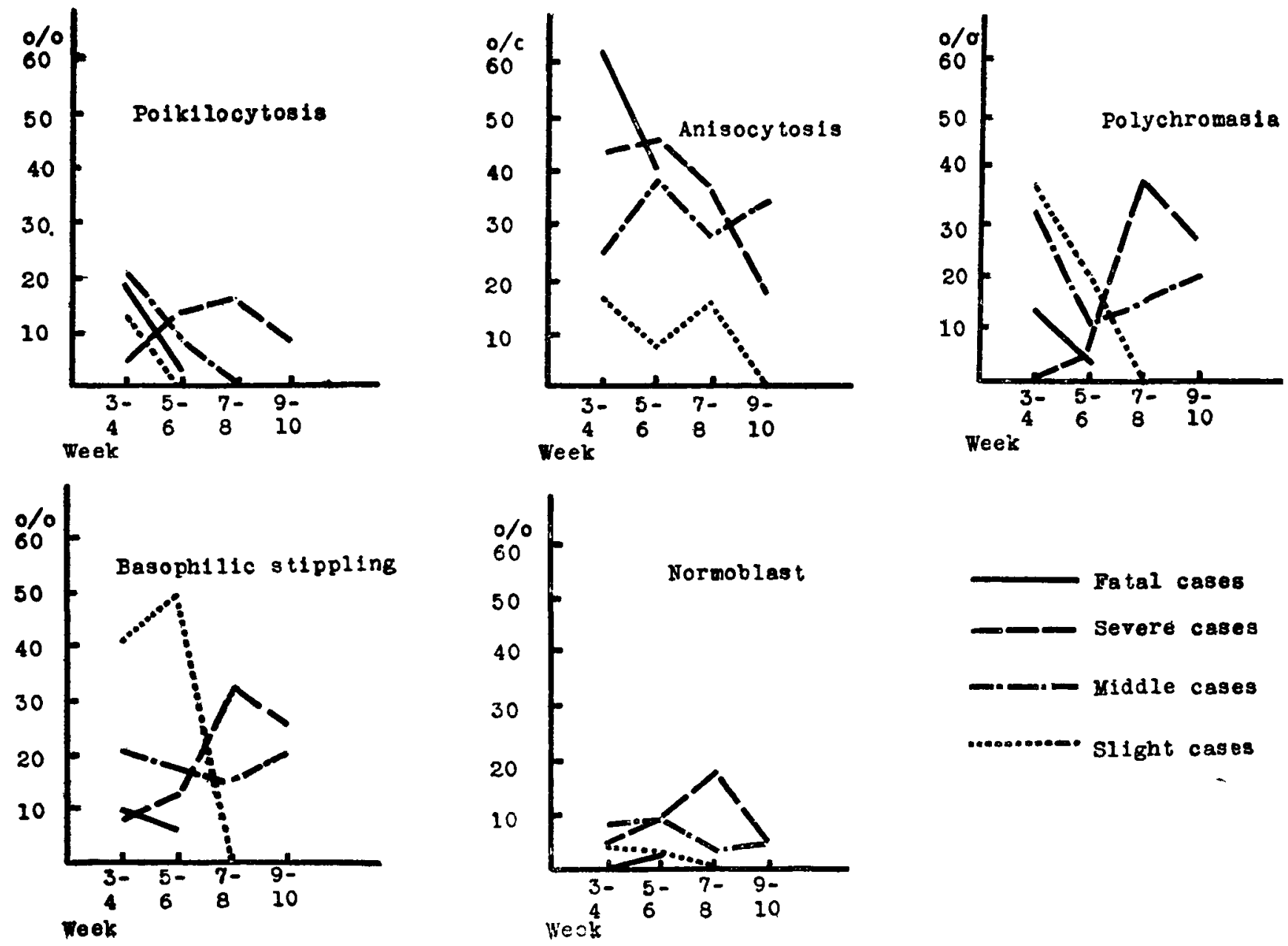
was found in $4.4 \%$ in the 3 . to 4 . week, in $16.3 \%$ in the 7 . to 8 . week, and thereafter it decreased in percentage. In middle and slight cases it disappeared in the 5 . to 8 . week, namely earlier than in severe cases. Polychromasia and basophilic stippling were also not so pronounced. In the 3 . to 4 . week, they were observed in higher percentage in middle and slight cases than in fatal and severe cases. Thereafter they became less prominent in middle and

Table 3 Diameter of erythrocyte

\begin{tabular}{|c|c|c|c|c|}
\hline \multirow{2}{*}{ 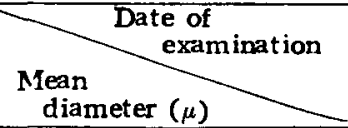 } & \multicolumn{2}{|c|}{ September, 1945} & \multicolumn{2}{|c|}{ September, 1946} \\
\hline & $\begin{array}{c}\text { Number of } \\
\text { cases }\end{array}$ & $\%$ & $\begin{array}{c}\text { Number of } \\
\text { cases }\end{array}$ & $\%$ \\
\hline Over 9.0 & 2 & 5.8 & 0 & $\underline{0}$ \\
\hline $8.9-8.5$ & 2 & 5.8 & 0 & $\mathbf{0}$ \\
\hline $8.4-8.0$ & 11 & 32.3 & 0 & 0 \\
\hline $7.9-7.5$ & 15 & 44.5 & 31 & 62 \\
\hline $7.4-7.0$ & 4 & 11.6 & 19 & 38 \\
\hline under 6.9 & 0 & 0 & 0 & 0 \\
\hline $\begin{array}{cc}\text { Date of } \\
\text { examinat ion }\end{array}$ & \multicolumn{2}{|c|}{ September, 1945} & \multicolumn{2}{|c|}{ September, 1946} \\
\hline Mean diameter & \multicolumn{2}{|c|}{$7.968 \mu$ (34 cases) } & \multicolumn{2}{|c|}{$7.572 \mu$ (50 cases) } \\
\hline Max. mean diameter & \multicolumn{2}{|c|}{$9.442 \mu$} & \multicolumn{2}{|c|}{$7.915 \mu$} \\
\hline Max. diameter & \multicolumn{2}{|l|}{$12.5 \mu$} & \multicolumn{2}{|l|}{$10.0 \mu$} \\
\hline
\end{tabular}

Fig. attached to Table 3 Diameter of erythrocyte

(Price-Jones curve)

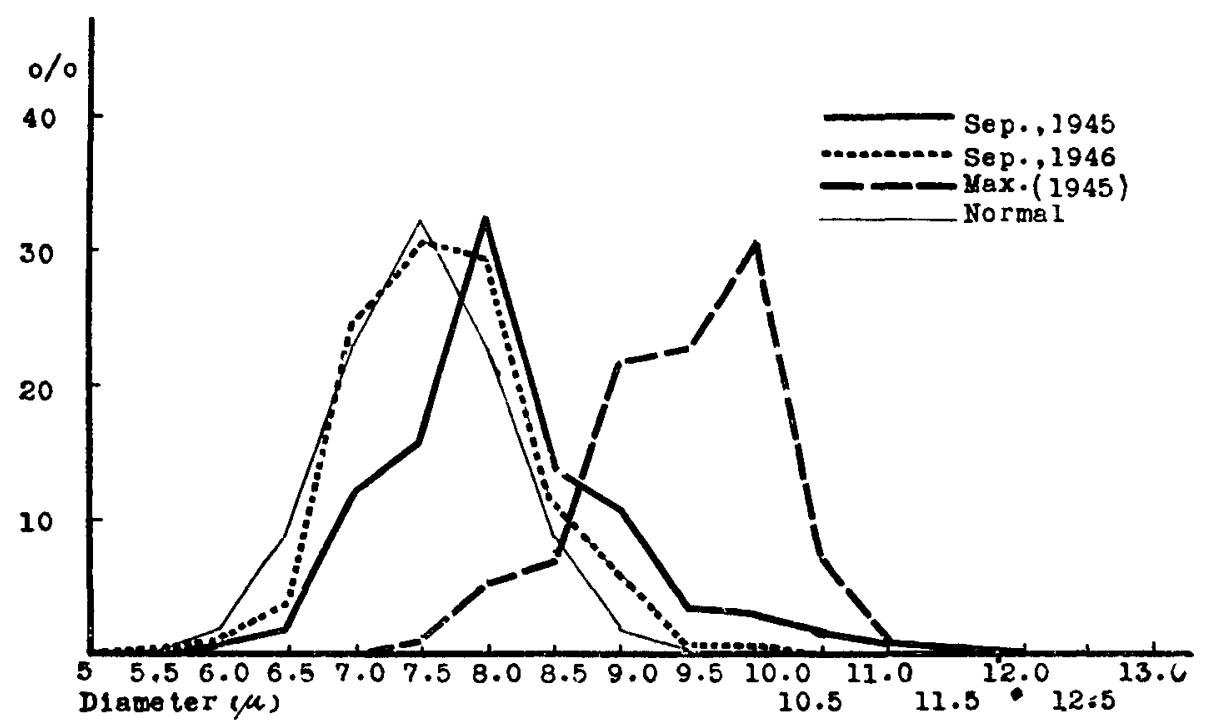


slight cases, while in severe cases, they became more prominent with the lapse of time, reaching the acme in the 7. to 8. week, and then decreased in their degree with the recovery of anemia. Normoblasts were found in some cases. They appeared more frequently in severe cases than in middle and slight cases. They were most frequently found in the 7 . to 8 . week. The diameter of erythrocyte was usually enlarged. The mean diameter of erythrocyte of 34 cases examined in the 4 . to 6 . week was $7.968 \mu$ in average, the largest

Fig. 8 Morphological changes of platelets

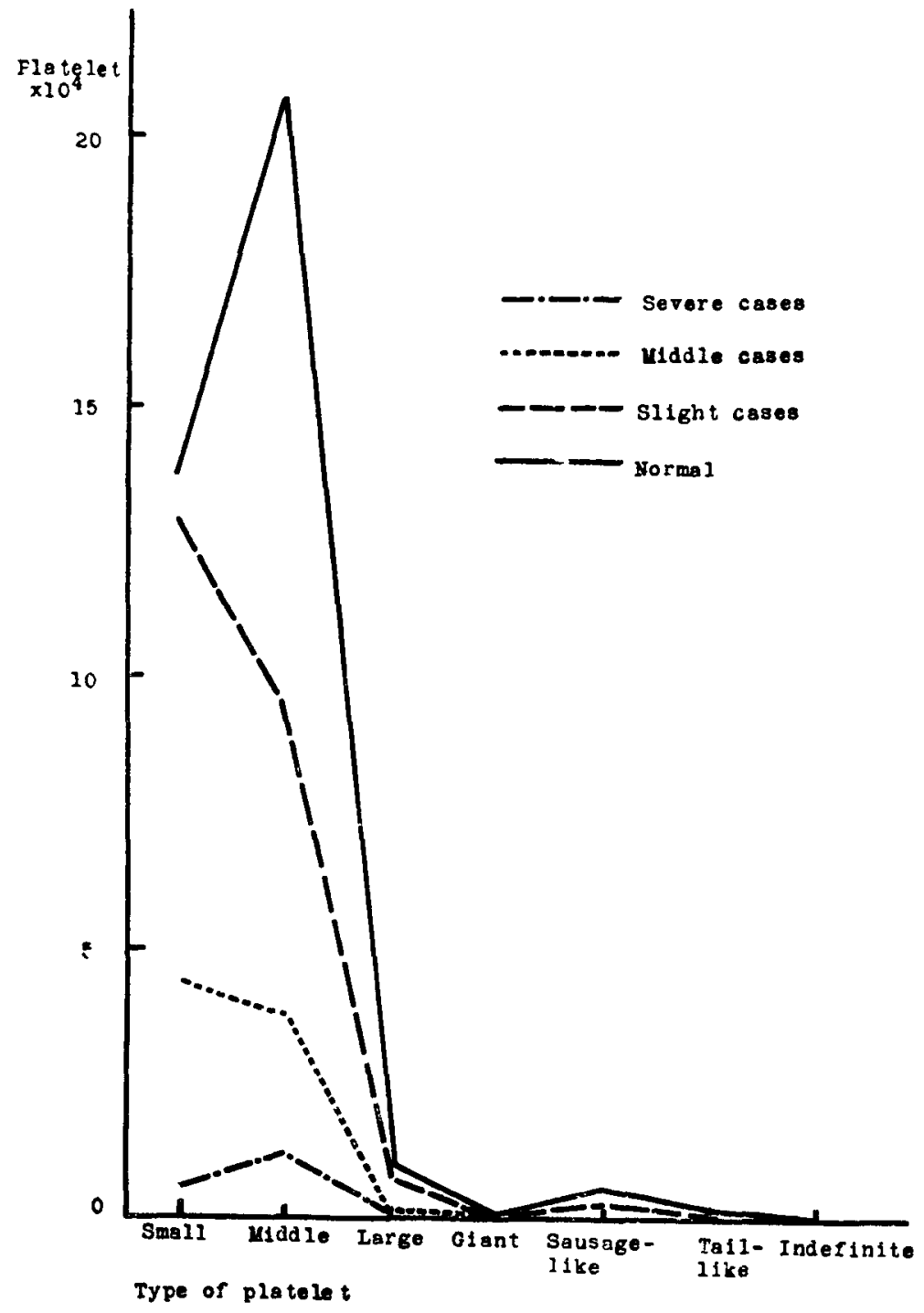


mean diameter being $9.442 \mu$ (Table 3 and attached figure).

Platelets. The decrease of the platelet count was remarkable in proportion to the severity of the disease. Morphologically observed, all the small, middle and large types of platelets were decreased, especially the decrease of the small and middle type was remarkable (Fig. 8). They showed degenerative changes such as poor staining, diminution of Azur granules and the like. At the recovery stage, the platelet count increased temporarily above normal in some cases.

Hemorrbagic diathesis. Hemorrhagic diathesis was one of the most important symptoms of radiation sickness. Hemcrrhages were observed more frequently in severe cases, and most frequently in the skin. Bleeding from the gums was also observed in many cases. Epistaxis, hematemesis, hemoptysis, bloody diarrhea., hematuria and bleeding from the uterus were seen in some cases. The hemorrhagic tendencies appeared in most cases in the 3 . to 6 . week concurrently with fever or a little later than the fever. There was a close relation between the reduction of the platelet count and the appearance of hemorrhagic tendencies. As shown in Fig. 9, the more marked the thrombocytopenia was, the more frequently the hemorrhagic tendencies were observed.

Fig. 9 Relation between hemorrhagic symptoms and platelet count

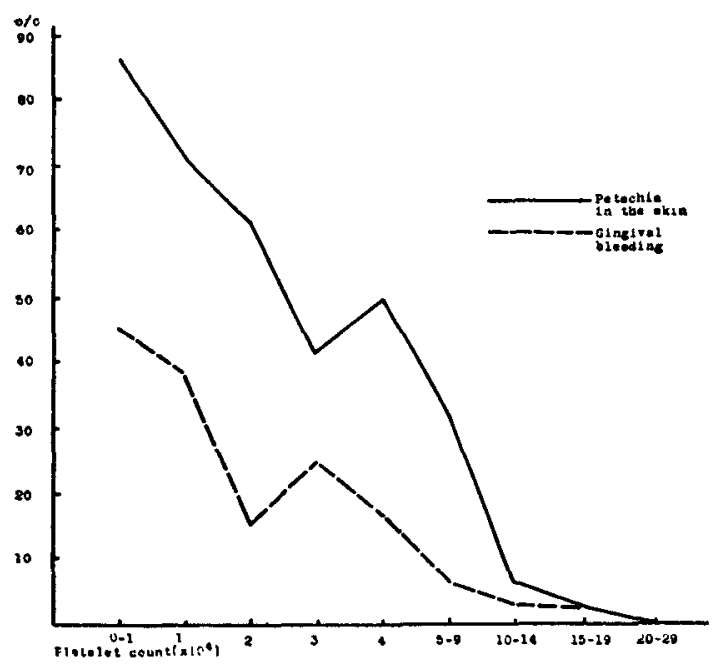

The bleeding time was remarkably prolong. ed in severe cases. As shown in Fig. 10, the prolongation of the bleeding time was observed in cases with the platelet count less than 100,000 per $\mathrm{cmm}$, and the bleed. ing time became longer in proportion to the decrease of the platelet count. With the recovery of the platelet count, the prolongation of the bleeding time became less prominent, and it returned to normal in

the 9. week even in severe cases. The agglutinative and retractile functions of platelets were markedly lowered in severe cases. ${ }^{10)}$ The thrombi-formation time was remarkably prolonged 
in severe cases. The coagulation time was moderately prolonged in severe cases, while it was usually normal in middle and slight cases. ${ }^{11)}$ The plasma prothrombin was decreased moderately in severe cases, while in slight cases it was normal or

Fig. 10 Relation between bleeding time and platelet count only slightly decreased. The Rumpel-Leede's phenomenon was moderately positive in severe cases. ${ }^{10)}$ The resistance of capillary wall, tested by means of the Borbely's method, was lowered only in a few cases. From the laboratory findings mentioned above, the main cause of the hemorrhagic diathesis in radiation sickness should be ascribed to the reduction of the platelet count. However, the other factors, such as disturbance of blood clotting, lowered resistance of blood capillaries, etc. must not be neglected.

The resistance of eryth-

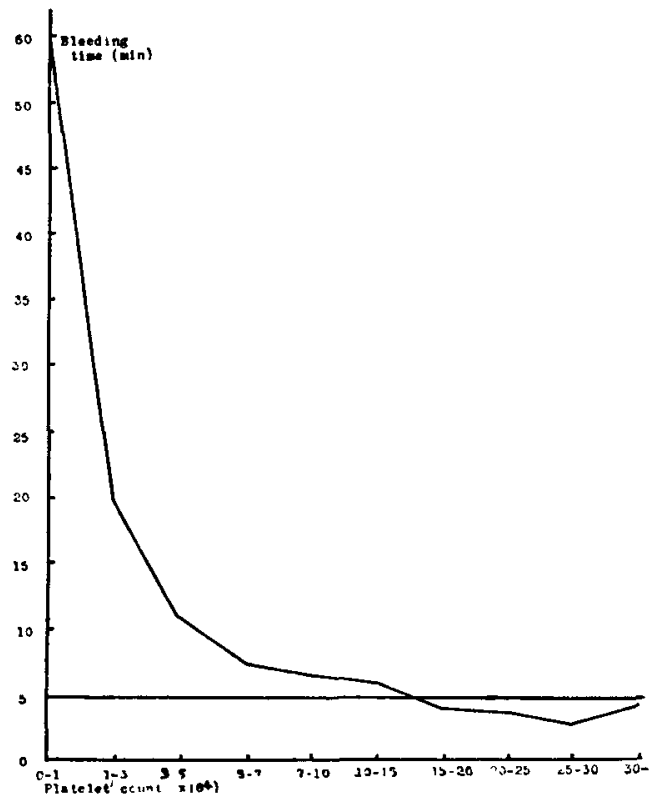

rocyte against hyposmotic salt solution showed usually no remarkable change, although in a few cases decrease of the minimum resistance or the maximum resistance was observed.

The sedimentation rate of erythrocyte was remarkably accelerated in severe cases. There was generally a parallelism between the degree of leukopenia on one side and the degree of the acceleration of sedimentation rate, prolongation of bleeding time and the decrease of the erythrocyte count on the other. There were, however, not a few cases with the leukocyte count less than 4000 per $\mathrm{cmm}$, in which the sedimentation rate, bleeding time and erythrocyte count were in the normal range. Therefore as an indicator for radiation injuries, the leukocyte count seems to be most userul. ${ }^{10}$

Relation between the leukocyte count, sedimentation rate and bleeding time on cne side and the distance trom the bombing center on the other (Fig. 11).

We made a mass examination about 617 cases in Hiroshima City from September 10. to September 16., 1945, namely 6 weeks arter the 
Fla. Il Rejatłan betwen the leukcocyte count, iedimeatation rats, bleating tiuce and the distance from the bombing ceater

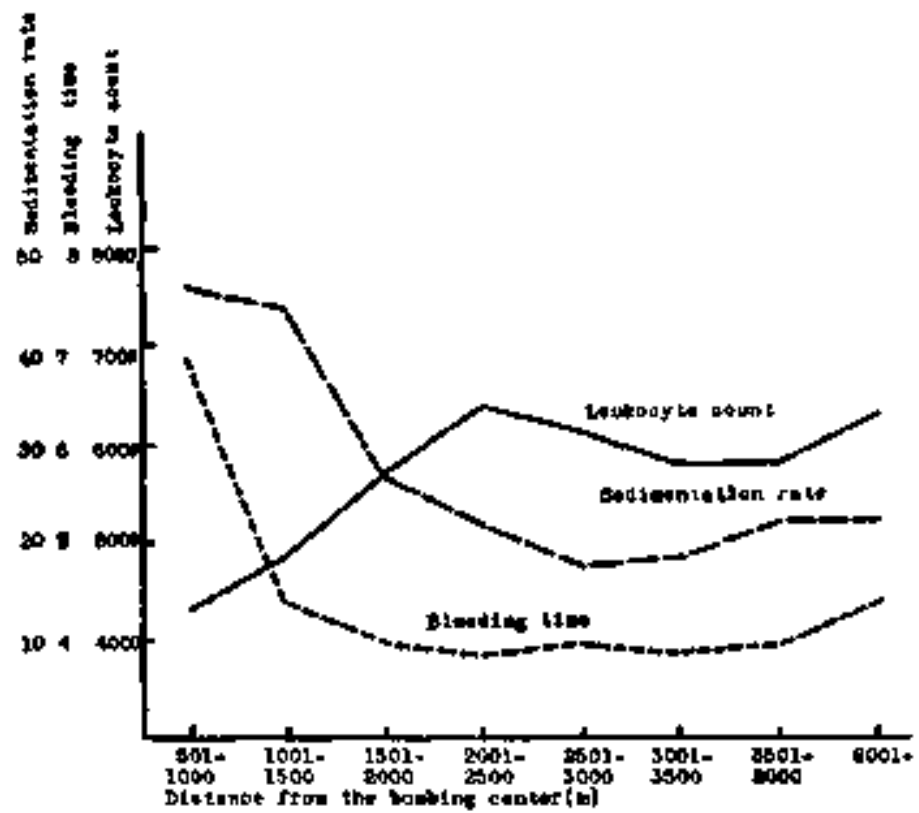

bombing. The average leukocyte count of 617 cases was 6025 per cmm, and the closer the individuals were to the bombing center at the time of explosion, the more ramarkable was the reduction of the averace leukocyte count. There were not a few cases showing leukopenia without any subjective or objective symptom.

As shown in Fis. 11, the average vaitue of the sedimentation rate was accelerated in inverse proportion to the distance from the bombing center, and the average value of the bleeding time was more markedly prolonged in inverse proportion to the bombing center.

Bacteriological examination of blood. At the acme of radiation sickness showing sepsts-like symptoms such as high fever, hemorrhagic tendencies, necrotic gingivitis and tonsillitis, pyogenic bacteria (bemolytic streptococcus, streptococcus viridans, staphylococcus and colon bacillus) were cuitivated from the blood in not a few cases. Judging from this result, at least some severe cases should be considered to have been complicated by sepsis.

\section{Canges of bone matrow pieture.}

In severe cuses the number of nucleated cells were markedIy reduced, ranging from 5000 to 20,000 per $\mathrm{cmm}$ at the acme of the 
disease. The erythropoietic function was greatly disturbed. The inmature cells such as proerylhroblasts, basophilic macroblasts and basophilic notmoblasts were especially very scarce or had almost dissppeared. In the leukopoietic series, the neutrophils were reinar. kably decreased. Especially the decrease of the immature forms such as promyelocytes and myelocytes was pronounced (Fig. 12),

Fle. 12 Bone marrow picture

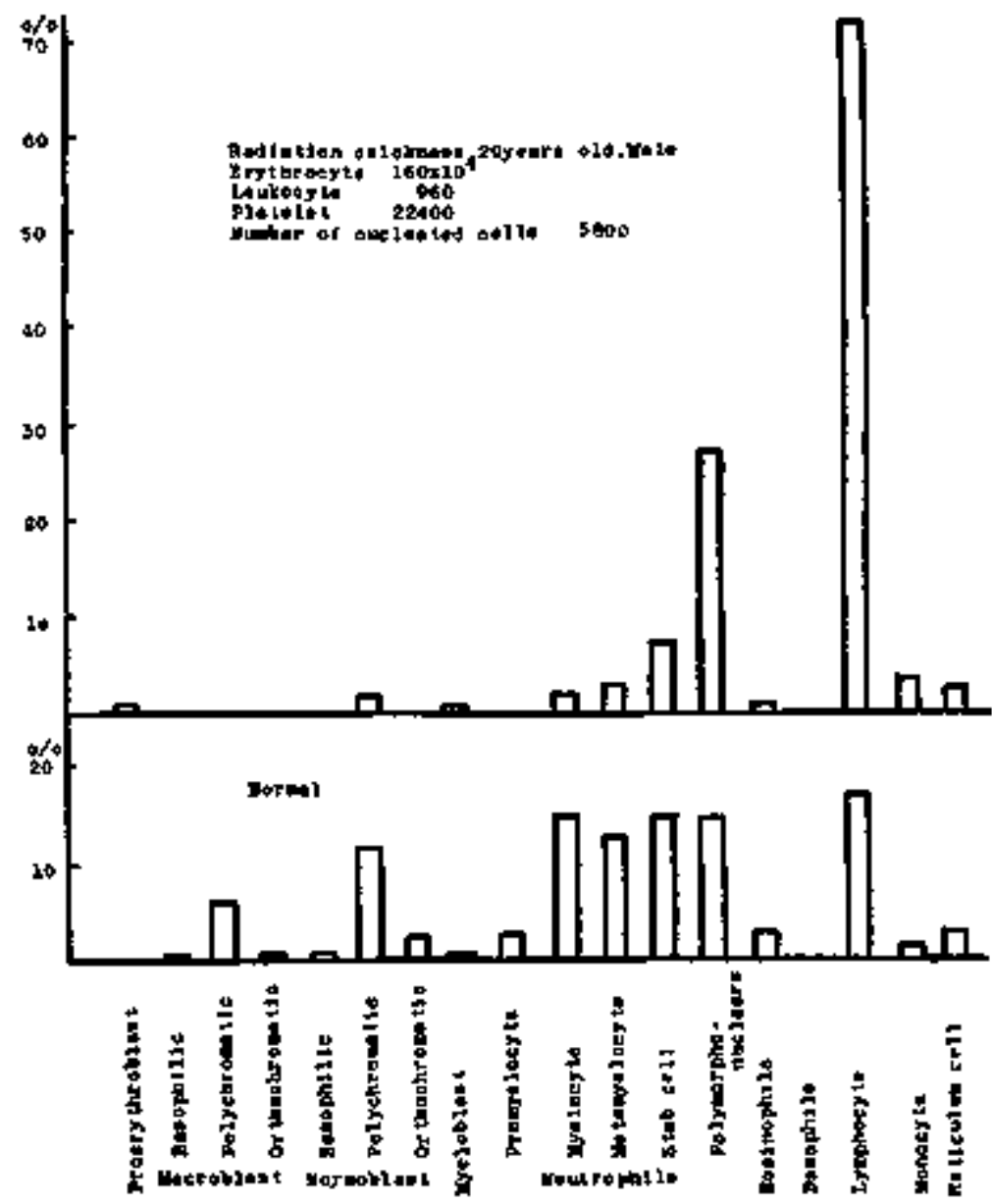

There remained chietly the mature celts such as metamyelocytes, stab cells and polymorphonuclears. The eosinophils were also reduced or disappeared. In the granulocytes there were observed, as in the peripberal blood, various degenerative changes atch as vactola. tion, toxic granules, pyknosis or obscure structure of nuciei, increase of nuclear shadow and the like. Contrary to the decrease of the 
granuolocytes, the lymphocytes were increased in percentage. The monocytes, plasma cells and reticulum cells were also often increased in percentage.

The megakaryocytes were markedly decreased. The megakaryocytes which were found were mostly of the mature or transitional type. The immature types such as promegakaryocyte and megakaryoblast were very rare. Sometimes masses of protoplasm without nuclei or naked nuclei were seen. The megakaryocytes showed often vacuolation. Their nuclei were sometimes distorted, and the thrombopoietic function was markedly impaired.

In middle cases on the way to recovery the percentage cif the erythropoietic series was normal or increased above normal, and the proerythroblasts, basophilic and polychromatic macroblasts as well as normoblasts were tound in sufficient number. In the leukopoietic series, the percentage of the neutrophils was almost normal or only slightly decreased, and there were found not only the polymorphonuclears and stab cells but also the metamyelocytes and promyelocytes in sufficient number. These findings show that both the erythropoietic and leukopoietic function of the bone marrow were on the way to recovery. The ecsinophils, which were decreased in the acme of the disease, were found increased with the recovery of the leukopoietic function. The increase of the percentage of the lymphocytes was less pronounced. The decrease of the megakaryocytes was also less prominent. The immature types of megakaryocytes appeared, and the thrombopoietic function was on the way to recovery. In short, the bone marrow function was markedly injured in severe cases. The immature forms of bcth the erythropoietic and leukopoietic series were especially injured severely. The thrombopoietic series were also injured. These changes of the bone marrow seemed to precede the changes of the peripheral blood picture, as revealed by the follow-up examination of the sternal bone marrow and the peripheral blood.

\section{Etiological considerations.}

The ionizing radiaticns produced by the explosion of the atomic bomb may be classified as follows : ${ }^{4}$

1) High energy $\gamma$-rays and neutrons released by the chain reaction.

2) $\gamma$-rays originating in capture reactions.

3) Neutron-induced radioactivity produced in the matters on the ground and tissues of the human body. 
4) Fission products formed in the chain reaction.

Among these ionizing radiations, 1) and 2) are regarded as the main cause of radiation sickness. According to the report of the Pathological Institute of Kyoto University ${ }^{12)}$ and others ${ }^{13)}$, however, induced radioacticity was found in the bones and other various tissues of the patients who died of radiation sickness. How much influence this induced radioactivity exerted upon the development of radiation sickness is not known. Some researches ${ }^{23}$, however, stated the opinion that the induced radioactivity, especially that of radiophosphorus produced in the body by the reaction ${ }_{15} \mathrm{P}^{31}+{ }_{0} \mathrm{n}^{1} \rightarrow{ }_{15} \mathrm{P}^{32}$, might have had some influence upon the hematopoietic organs in the fatal cases which were bombed at a distance very close to the bombing center.

Be that as it may, the effects of the ionizing radiations mentioned above upon the human body are regarded identical in principle as the effects of $\mathrm{X}$-rays ${ }^{(4), 15), 167,17), 187,193,203,217,48)}$, and it has long been known that the most sensitive organs to these ionizing radiations are the hematopcietic organs, the gastrointestinal tract, the hair follicles and the gonads. ${ }^{16), 18), 30)}$ Therefore the observation of the effects of large doses of X-ray irradiation upon animals will contribute to the understanding of the symptoms of radiation sickness caused by the atomic bomb. Fig. 13 shows the changes of the peripheral blood picture of a rabbit exposed to a large dose $(3000 \mathrm{r})$ of $\mathrm{X}$-rays.2) As shown in the iigure, the lymphocytes decreased remarkably immediately after the irradiation. The heterophils also decreased markedly, aiter showing a temporary increase following the irradiation. The eosinophils also decreased. The plasma cells were irequently observed. The erythrocyte count decreased. The decrease of the erythrocyte count, however, was not so remarkable as that of the leukocyte count. The reticulocyte almost disappeared two days after the irradiation. The platelet count began to decrease a little later than the leukocyte count. The phagocytic and migrating functions of the heterophils were lowered.

These changes of the peripheral blood picture are identical with those in radiation sickness caused by the atomic bomb. From the results of the stuby of bone marrow pictures in man and animals exposed to the atomic bomb ${ }^{13}, 33,103,12$ ), as well as from the results of the pathological and histological examination of their hematopoietic organs ${ }^{5,12), 20), 23), 24), 25)}$, it is evident that these changes of the peripheral blood picture as mentioned above were caused by the injuries of the hematopoietic organs such as the bone marrow, spleen and lymph 


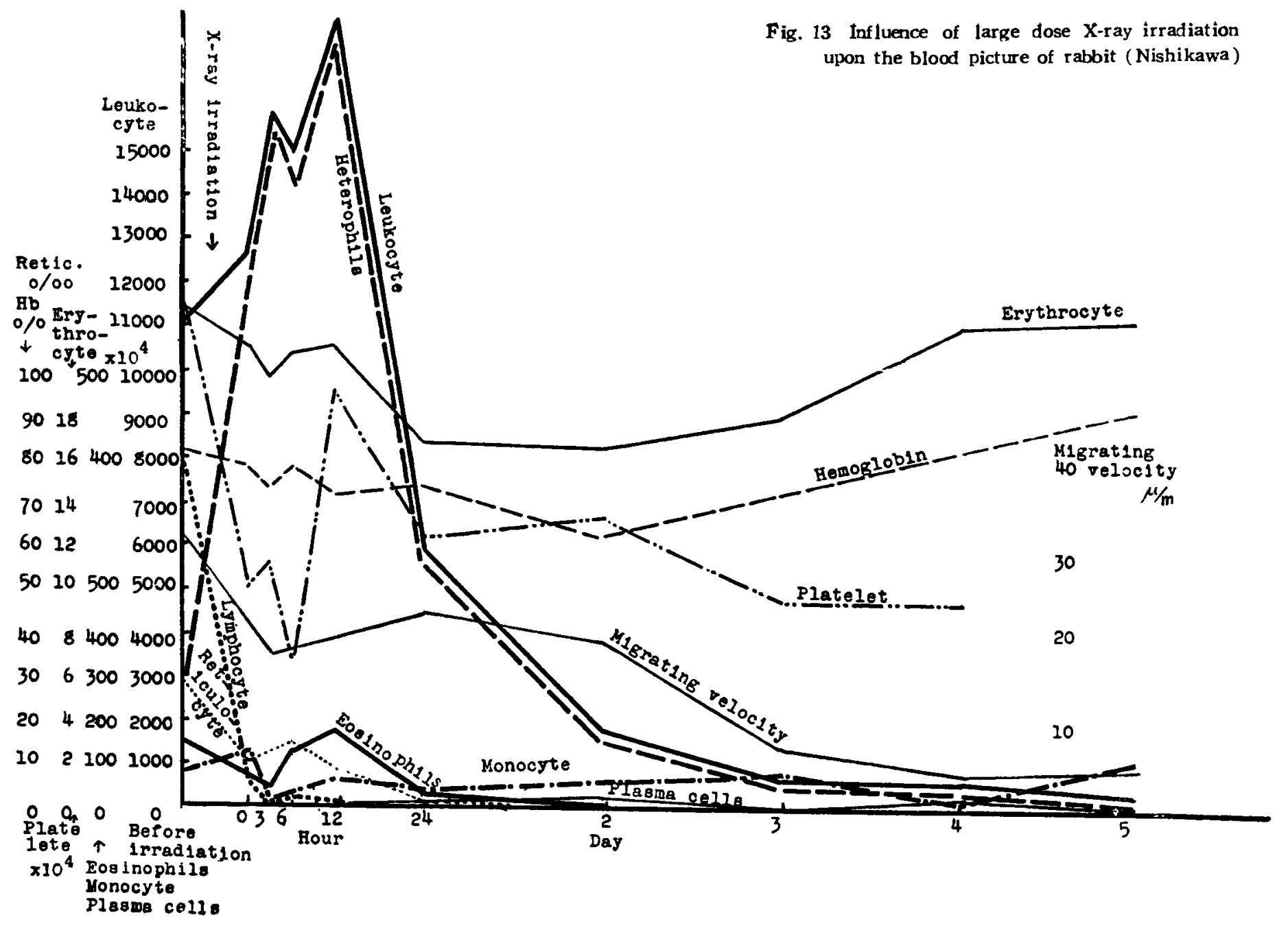


nodes. In short, these changes may be called "panhematophthisis." Necrotic gingivitis or pharyngitis, which is one of the most important symptoms of radiation sickness, may be attributed to the secondary bacterial infection due to the lowered resistance as a result of the reduction of leukocytes. Hemorrhagic diathesis, which is also one of the most important symptoms of radiation sickness, may be considered to have been caused chiefly by the reduction of the platelet count. Therefore it seems not too much to say that the clinical picture of the atomic bomb radiation sickness is based on the injury of the hematopoietic organs caused by the ionizing radiation of the atomic bomb.

The other important symptoms of radiation sickness such as epilation, diarrhea and disturbance of the sexual function may be well understood from the sensitivity of the organs to radiation. Furthermore the toxemia caused by tissue destruction and bacterial infection, functional disturbance of various organs, diarrhea and vomiting due to injuries of the gastrointestinal tract, loss of body fluid and disturbance of nutrition and acid-base balance may be considered to have had great influence upon the course and prognosis of radiation sickness. The early symptoms such as nausea, vomiting, general malaise and diarrhea, which occurred immediately aiter the bombing have long been well known in radiologists as an effect of radiation.

\section{Course and prognosis}

According to the statistics made by Masuyama, ${ }^{2}$ (9) $\%$ of the deaths caused by the atomic bomb occurred within forty days after the bombing. Most of the deaths which occurred on the day of the bombing or within a few days after the bombing were caused by severe mechanical injuries, burns, or radiation sickness or combination of two or three types of these injuries. The deaths after two or three weeks following the bombing, however, were caused chiefly by radiation sickness, especially by the destruction of hematopoietic organs accompanied by secondary bacterial infection. After three months following the bombing, bacterial infections such as pneumonia, gangrene of the lung and sepsis, malnutrition, and in some cases aplastic anemia were listed as the cause of death. It must also be noted that leukemia, though rare in number, was reported as the cause of death at this stage. ${ }^{26)}$ 27)

As for the relation between the changes of blood picture and the prognosis of radiation sickness, the more remarkable the leukopenia, 
anemia and thrombocytopenia were, the mcre unfavourable was the prognosis. Those who showed a leukocyte count less than 1000 per $\mathrm{cmm}$ had usually unfavourable prognosis, although there were not a few cases which recovered from a leukccyte count less than 1000 per $\mathrm{cmm}$. At an early stage, there was no relation between the count of eosinophils and prognosis. Three to four weeks aiter the bombing, when the typical radiation sickness developed, however, the disappearance of the eosinophils showed an unfavourable prognosis, and the reappearance or increase of the eosinophils showed a favcurable prognosis. The increase of the monocytes was also regarded as a sign of good progncsis.

The relation between burns and radiation sickness.

Some researchers declared that burns had scme iavcurable influence upon radiation sickness. According to the report cit the Research Corps of Tokyo University," petechiae were found less frequently in cases with burns than in those without burns in the area beyond $2 \mathrm{~km}$ from the bombing center in Nagasaki City, indicating that burns had an suppressing effect upon the appearance of petechiae.

Changes of the blood picture as related to the course of radiation sickness.

From the results of the observation mentioned above, it may be concluded that the changes of the blood picture following exposure to the atomic bomb appeared at first in leukocytes. The decrease of the leukocyte count, especially that of the lymphocytes, was observed already at the early stage. The decrease of the granulocytes began a little later than that of the lymphocyte. Whether or not there was an initial granulocytosis immediately after the bombing is not known. The decrease of the platelet count appeared a little later than that of the leukocyte, and the decrease of the erythrocyte count was observed a little later than that of the platelet. At the recovery stage, the leukocyte increased rapidly in number. The increase of the granulocytes was especially rapid. The eosinophils were frequently increased. Contrary to the rapid increase of the granulocytes, the recovery of the lymphocytes was usually slow, and there were not a few cases in which the lymphocyte count was not restored to normal even aiter ten weeks following the bombing. The recovery of the platelet and erythrocyte count seemed to have been delayed as compared with that of the leukocyte. At the recovery stage, there were some cases which showed a temporary leukocytosis or fluctuation of the leukocyte count. In a few cases the 
recovery of the leukocyte count was extremely delayed.

These changes of the peripheral blood picture were the same as those observed in animals exposed to radiation, and well understandable from the histological changes of the hematopoietic organs of these animals and of the patients who died from radiation sickness.

\section{Treatment.}

From the pathogenesis of radiation sickness as mentioned above, the main objectives in the treatment of the patients are ; ${ }^{83}$ 30)

1) to maintain adequate fluid and acid-base balance

2) to eliminate toxic substances from the body

3 ) to control infectious processes

4) to combat the hemorrhagic phenomena and

5 ) to stimulate the hematopoietic function.

For the purpose of 1 ) and 2) injections of glucose, fructose, physiologic salt solution, Ringer's solution, vitamin $\mathrm{B}, \mathrm{C}$, and transfusion of whole blood or dry plasma were used. Penicillin was effective to control the infections. ${ }^{3)}$ Streptomycin, ${ }^{31)}$ aureomycin ${ }^{32)}$ and other antibiotics would also be effective. To combat the hemorrhagic phenomena, local treatment as well as blood transfusion and injections of vitamin $K, P, C$, calcium and various blood coagulants were tried. Recently it has been reported that protamine sulfate and toluidine blue are effective to control the hyperheparinemia, which is presumed as one of the causes of the hemorrhagic tendencies in radiation sickness. Rutin may be used for increased permeability of blcod capillaries. For the purpose of stimulating the hematopoietic function, blood transfusion, intrasternal blood transfusion, autotransfusion, crude liver, liver preparations, gastric mucosa of swine, bone marrow preparations, reduced iron, nucleinacidic sodium, vaccine, omnadine and moxibustion were tried. Among these therapeutic procedures and medicaments repeated blood transfusion and liver preparations were reported to be effective. We also confirmed the effectiveness of blood transiusion in cases with marked leukopenia less than 1000 per $\mathrm{cmm}$.

Folic acid, vitamin $B_{12}$ and cysteine may be also indicated to stimulate the hematopoietic function. Hormones of the adrenal cortex and pituitary gland were used in some cases, and it was reported that the former had a favourable influence upon radiation sickness.") We tried further preparations of the parathyroid gland, calcium carbonate and phosphorus containing medicaments to accelerate the excretion of radicactive substances from the body. The 
observation term, however, was too short to cosfirm their effect. Needless to say, that rest, sufficient nutrition and symptomatic treatment were necessary for the rapid recovery of radiation eickness.

Prophylaxis. Adequate shelter such as lead, iron and conctete will be usoful to protect the ionizing radiations produced by the explosion of the atomic bomb. Recently it was reported that

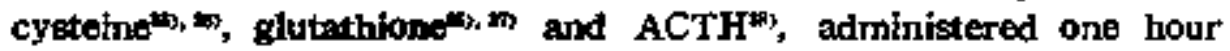
before the irradiation, was effective to alleviate radjation sickness.

Influenes of the reajdual radistion.

1) Examination of the leukocyte count of tbose who entered Hiroshima City soon after the bombing.

Among 20 persons who wexe far away from Hiroshima. City at the time of bornbing, but entered there soon after the bombing and engaged in the disposal of corpses and cleaning up of debris near the hombing center, we found 3 cases with the leukocyte count from 2000 to 3000 per cmm, and one with the leukocyte count from 3000 to 4000 per cmum."' Putting together various reports, we could find leukopenia less than 5000 per $\mathrm{cmm}$ in $32.3 \%$ of 62 persons who entered Hitoshima City within one week after the bombing. It will be too much to say that all of these leukopenias were cuused by the residual radiation. It could not be denjed, however, that the residtual radiation had some influence upon the human body soon after the bombing, although there was no case in which the jnjury was so severe as to result in death.

2) Influence of the fission products.

An area, called "Nishiyama" in Nagasaki City, was protected from tbe direct radiation effect of the atomic bomb, because this area was bohind Mt. Kompita on the opposite side of the bombing center. By fallen fisston products, however, radioactivity about 200 to 300 times as strong as the natural radioactivity was found in this area at the investigation on October 1, 1945, and several radioisotopes such as $\mathrm{Sr}^{*}, \mathrm{Ba}^{\prime *}, \mathrm{Ce}^{\mathrm{HM}}, \mathrm{Zr}^{*}$ and $\mathrm{Pr}^{1+4}$ were discovered in the soils of this area" According to the examination made by the membesr of the Radjological Department of Kyushu University, most of the people in this area showed a leukocytosis fifty to eighty days after the bombing. The leukocytosis reached from 30,000 to 50,000 per cmm in some cases. At the first examination on October 1,1945 . the leukocytosis was most frequently seen in children, and next to thern it was frequently observed in young and middle-aged persons, 
while aged persons above fifty years showed no leukocytosis. At' the second examination in January 1946, namely five months after the boubing. leukocytosts was also obsorved in aged persons, while in children leukncytosis was found less frequently as compared with the result of the first examinadion.

In our investigation in Novomber, 1946, we could confirm in Nishiyarot area radicactivity 5 to 30 ttmes as strong as the natural radjoactivity. The leukocytosis seemed to be declining, showing its acme in Jantury or April, 1946. At the examination in February. 1947, howerer, thore wore still not a few cases with leukocytosis in this area. ${ }^{40}$ The leukocytosis was found in $51 \%$ of the examined persons. As for the differential count, slight ecoinophilfa, shift to the left of the neutophils and sometimes a small number of metamyelocyt es were found. The immature cells younger than metamyelocytes were nat observed. Slight polycythemia (more than 5.5 million per cmm) was found in $10 \%$ of the examined cases. There was no change in the reticulocyte and platelet count. The leukocylosis was found even in the residents who came to this area after the bombing, and it is supposed to have been caused by the weak, but long lasting residual radiation in this area. The changes of the blood picture of the people in Nishiyama area seem to need further investigation, because it has as yet not been confirmed in radiology that permarnont leukocytosis can be callsed by a primany stimulating effect of radjation ${ }^{16}$, $173 \mathrm{~m}$

Fifects of the atomic bomb one year after the bombing.

We examined 528 cases of the atomic bomb sufforers in Hiroshjma City from August 19. to September 10, 1946, and compared the result with that of the control (173 bealthy individuais in Hirdesima City, who did not encountered the atomic bomb explosion). Among the atomic bornb sufferers, there were many cases which complained of general malaise, vertigo and palpitation even one year after the bombing, and in a rew cases hemorrhagic diathesjs was observed. As for the blood picture, decrease of the erythrocyte count, elevation of the colcr index, decrease of the leukocyte and platelet count were more frequently seen in the atomic bomb sufferers than in the control. These differences were statistically significant. SNELE, NEEL and IsHIBASHI ${ }^{22}$ have also reported that the exythrocyto count. hemoglobin concentration, hematocrit reading and iymphocyte count were slightly, but significantly depressed in the atomic bomb auf. ferers in Hiroshima City twenty to thirty-tbree months after the bonbing as compared with the control in Kure City, which is located 
Fig. I4 Erythrocyte count one and rwo gearg after the bombing

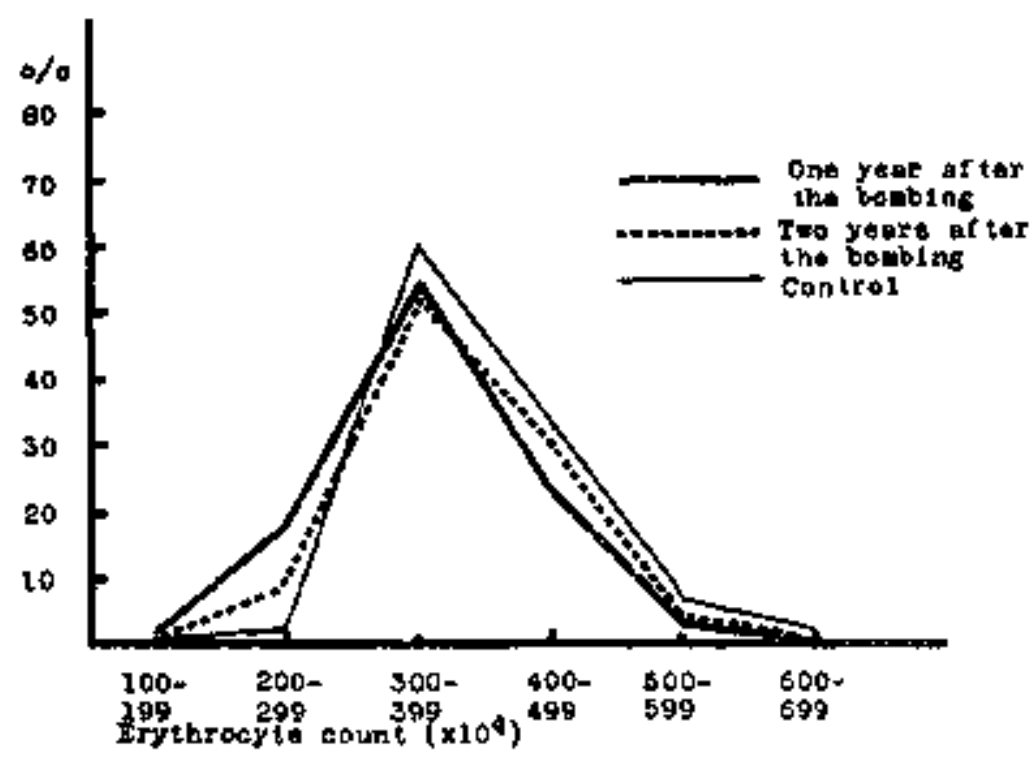

Fig. Is Color index ane and two years after the bombian

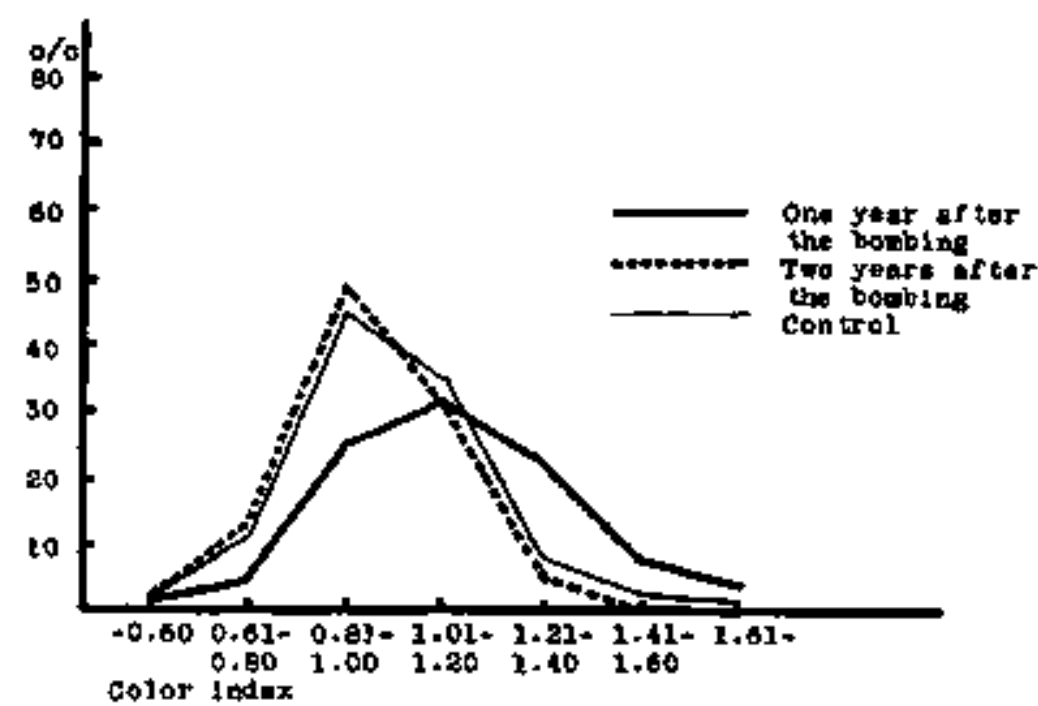

18 miles from Hiroshirna City.

In our ithvestigation of sternal bone marrow, there were some atomic bomb sufrerers with impaired bone marsow function. The phagocytic activity of the neutrophils was still lowered in some cases, but there were also some ceses with normal phagocytic 
Fig. 16 Leukacyte couml one and 1 wo yearn after the boubing

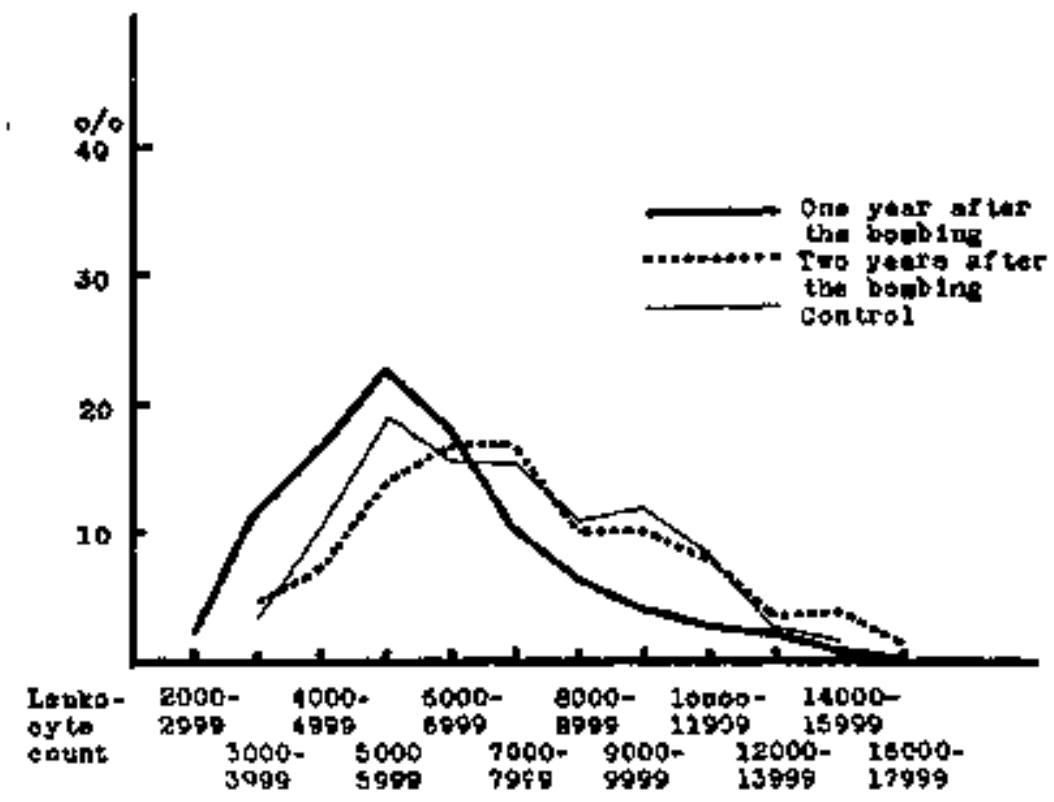

For. 17 Platelet coupt onf and two years ofter the bombth

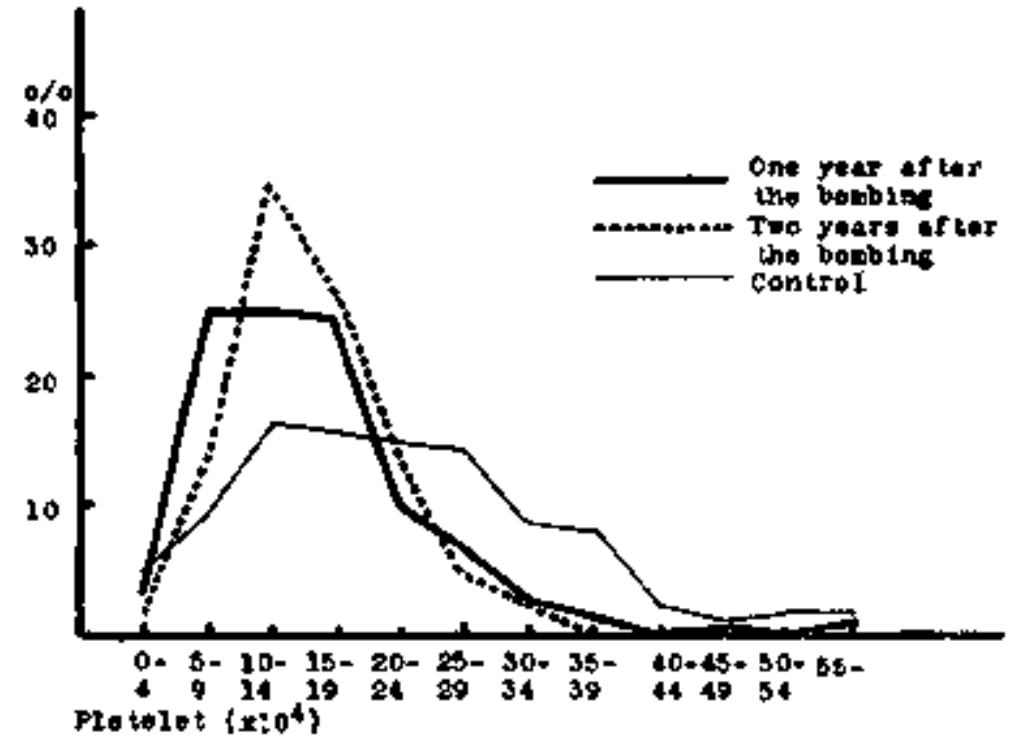

activity in spite of leukopenia. The migrating function of the neutrophils was generally lowered as compared with the control. The ralation between the migrating function and the leukocyte count was inderinite. 
We also examined 172 cases of the atomic bomb sufferes in Nagasaki City from November 30. to December 6, 1946, and compared the result with that of the control (45 healthy individuals in Nagasaki City who did not encounter the atomic bomb explosion). ${ }^{43}$ Among the atomic bomb sufferers there were not a few cases with anemia, leukopenia and thrombocytopenia. These changes, however, were not statistically significant as compared with the control.

Effect of the atomic bomb two years after the bombing.

We examined 243 cases of the atomic bomb sufferes in Hiroshima City from Octoder 10. to October 19, 1947, namely two years and two months aiter the bombing. ${ }^{4)}$ There were not a tew cases which complained of general malaise, vertigo and palpitation, although these complaints were not so frequent as in the previous year. Hemorrhagic diathesis was also observed in few cases. There were some cases with anemia, leukopenia, thrombocytopenia, prolonged bleeding time and impaired bone marrow function. These changes, however, were less frequent, and the phagocytic and migrating. functions of the neutrophils were also less impaired as compared with the previous year. From these results it may be concluded that the blood cells of the atomic bomb sufferes were on the way to recovery both quantitatively and functionally.

\section{Summary and conclusion}

Based upon the results of our investigation on the atomic bomb sufferers in Hiroshima and Nagasaki City, we described the acute and subacute radiation injuries caused by the atomic bomb as well as the influence of the atomic bomb one and two years aiter the bombing from the hematological point of view. Although the blood pictures of the atomic bomb sufferers were almost restored to normal two years after the bombing, there were still some cases with impaired hematopoietic functions. Furthermore it cannot be assured that the hematopoietic organs of those who have seemingly recovered from the atomic bomb injuries can meet the great demand just in the same manner as healthy individuals, when they are exposed to profound injuries, such as severe infection, large hemorrhage, serious intoxication and the like.

It is also noted from the experiences in radiologists and animal experiments that leukemia can be provoked by radiation, ${ }^{45}$ (46) 47) and actually it is reported that the incidence of leukemia in the atomic bomb sufferers in Hiroshima City is higher than that of the control.99) 
Therefore we deem it necessary to observe the blood picture of the atomic bomb sufferers for a long time in future.

In conclusion the authors wish to express their deep-felt thanks to Prof. Tsuzuki and other members of the Special Research Committee on the Atcmic Bomb Disasters of the Education Ministry as well as to the aurhorities in Huroshima and Nagasaki City for their kind and hearty cooperation in performing our investigations. We are also greatly indebted to the authorities of many universities and hospitals, who kindly sent their valuable records for our use. Furthermore we express our profourd condolence for Prof. Maszimo, Prof. Sugirama, Assistant Professor OkUBo, Lecturer Shimamoto, Lecturer NishiYama and other 6 members of the Research Corps of Kyoto University, who lost their precious lives in the performance of their researches on the atomic bomb injuries in a natural disaster which swept away the Ono Army Hospital on September 17, 1945.

\section{References}

1) Kikuchi, T. and S. Kimoto, 1947 : Clinical observation of atomic bomb injuries. Report read before the Twelf th Congress of the Japanese Association of Medical science, April, 1947.

2) Tsuzuki, M., 1951 : Investigation of the atomic bomb disasters. Refort on the atomic bomb disasters., 1-49.

3) Sassa, K., 1951 : Clinical observation of the atomic bomb radiation sickness. Report on the atomic bomb disasters., 50-70.

4) Nakaizumi, M., 1951 : Radiation of the atomic bomb observed from the medical point of view. Report on the atomic bomb disasters., $71-78$.

5) Kinoshita, R. and H. Miyake, 1951 : Pathological and histological investigation of the atomic bomb injuries. Report on the atomic bomb disasters., 79-195.

6) Kure Naval Station, 1945 : Medical investigation of the atomic bomb disasters in Hiroshima City. Report to the Special Research Committee on the Atomic Bomb Disasters.

7) Military Medical College and First Tokyo Army Hospital, 1945 : Report on the medical investigation of the atomic bomb disasters in Hiroshima City. Report to the Special Research Committee on the Atomic Bomb Disasters.

8) Kikuchi, T., M. Fukase, S. Note, and R. Ishigami, 1945 : Report on the results of the examination of the atomic bomb sufferers in Nagasaki City. Report to the Special Research Committee on the atomic bomb Disasters.

9) Wakisaka, G., and M. Fukase, 1946 : Studies on the phagocytic function and peroxidase reaction of neutrophils and the mitochondria of lymphocytes in atomic bomb injuries. Read before the Spring Meeting of the Japanese Society of Hematology.

$10)$ Kikuchi, T., T. Okubo, S. Nishiyama, T. Sesaki, G. Wakisaka, T. Setsuda, S. Anzai, S. Itoi, J. Hamanishi, H. Ishigami, T. Nasu, Y. Shiokawa, M. Takeda, and S. Fujimura, 1945 : Clinical investigation of the atomicradiation sickness. (Results of the examination of the atomic bomb sufferers in Hiroshima City). Report to the Special Research Committee on the Atomic Bomb Disasters.

11) Kikuchi, T., T, Okubo, S. Nishiyama, T. Sasaki, J. Hamanishi, H. Ishigami, and M. Takeda, 1946 : Mass examination of the atomic bomb sufferers in Hiroshima City, especially on the relation between the distance from the bombing center and the leukocyte count, sedimentation rate of erythrocyte, bleeding time and clinical symptoms. Read before the Spring Meeting of the Japanese Society of Hematology. 
12) Sugiyama, S., S. Amano, et a1, 1945 : Pathological investigation of the acute and subacute injuries caused by the atomic bomb., Shimamoto, K. and Unno, G., Radioactive substance of the atomic bomb, especially on the induced radioactivity in human body., Aamano, S. et al, Bone marrow picture of the atomic bomb injuries. Report to the Special Research Committee on the Atomic Bomb Disasters.

13) Shinohara, K. and K. Ishikawa, 1945: Studies on the radioactivity of the atomic bomb and the influence thereof upon human body. Refort to the Special Committee on the Atomic Bomb Disasters.

14) Warren, S., 1946 : The pathologic effects of an instantaneous dose of radiation. Cancer Research, 6, 449-453.

15) Jacobson, L. O., and E. K. Marks, 1947 : The hematological effects of ionizing radiations in the tolerance range. Radiology, 49, 285-298.

16) Prosser, C. L., E. E. Painter, H. Lisco, A. M. Brues, L. O. Jacobson, and M. N. Swift, 1947 : The clinical sequence of physiological effects of ionizing radiation in animals. Radiolozy, 49, 299-313.

17) Bloom, W., 1947 : Histological changes following radiation exposures. Radiology, 49, 344-348.

18) Bloom, W., and L. O. Jacobson, 1948 : Some hematologic effects of irradiation. Blood, 3, 586-592.

19) Jacobson, L. O., E. K. Marks, and E. Lorenz, 1949 : The hematological effect of ionizing radiations. Radiology, 52, 371-395.

20) Tullis, J. L., 1949 : The response of tissue to total body irradiation. Am. J. Path., $25,829 \cdot 851$.

21) Howland, J. W., and S. L. Warren, 1948 : The effects of the atomic bomb irradiation on the Japanese. (Lawrence, J. H., and Hamilton, J. G., Advances in biolcgical and medical physics, 1, 387-408).

22) Nishikawa, M., Studies on the effect of X-rays upon the blood and bone marrow picture of rabbits. To be published.

23) Tullis, J. L., and S. Warren, 1947 : Gross autopsy observations in the animals exposed at Bikini. J. A. M. A., 134, 1155-1158.

24) Liebow, A. A., S. Warren, and E. De Coursey, 1949 : Pathology of atomic bomb casualties, Am. J. Path., 25, 853-1027.

25) Beck, J. S. P. and W. A. Meissner, 1946 : Radiation effects of the atomic bomb among the nations of Nagasaki, Kyushu. Amer. J. Clin. Path., 16, 586-592.

26) Misao, T., Y. Harada, and K. Hattori, 1946: A case of monocytic leukemia after atomic bomb injuries. Acta haematologica Japonica, 9, 93.

27) Komiya, E., and S. Yamamoto, 1947 : Report of an acute leukemia following atomic bomb injuries. "Diagnosis and Treatment" (Shindan to Chiryo) 36, 88-91.

28) Le Roy, G. V., 1947 : The medical sequelae of the atomic bomb explosion. J. A. M. A., 134, 1143-1148.

29) Warren, S., 1942 : Effects of radiation in normal tissues. Arch. Path., 34, 562-608.

30) Painter, E. E., and A. M. Brues, 1949 : The radiation syndrome. New Eng. J. Med., 240, 871-876.

31) Miller, C. P., C. W. Hammond, and M. Tompkins, 1950 : Reduction of mortality from X-radiation by treatment with ant biotics. Science, 111, 719-720.

32) Furth, F. W., M. P. Coulter, and J. W. Howland, 1952 : The effect of aureomycin on the radiaton syndrome in dogs. Am. J. Path., 28, 26-36.

33) Allen, J. G., and L. O. Jacobson, 1947 : Hyperheparinemia : Cause of hemorrhagic syndrome associated with total body exposure to ionizing radiation. Science, 105, 388-389.

34) Alken, J. G., M. Sanderson, M. Milham, A. Kirshon, and L. O. Jacotson, 1948 : 
Heparinemia? An anticoagulant in the blood of dogs with hemorrhagic tendency after total body exposure to roentgen rays. J. Exp. Med., 87, 71-86.

35) Brues, A. M., 1952 : The physician in an atomic attack. The Medical Clinics of North America, 36, 263-272.

36) Patt, H. M., D. E. Smith, and E. Jackson, 1950 : The effect of cysteine on the peripheral blood of the irradiated rat. Blood. 5, 758-763.

37) Patt, H. M., D.E. Smith, E. B. Tyree, and R. L. Straube, 1950: Further studies on modification of sensitivity to X-rays by cysteine. Proc. Soc. Exp. Biol. \& Med., 73, 18-21.

38) Taber, K. W., 1951 : Treatment of radiation sickness with ACTH. A preliminary report of fourteen cases. Radiology, 57, 702-709.

39) Arakatsu, B., T. Hayashi and K. Nishikawa, 1947 : Residual radiation in Nagasaki City. Report to the Special Research Committee on the Atomic Bomb Disasters.

40) Kikuchi, T., M. Fukase, T. Sawada, R. Ishigami, and Y. Yamasoba, 1947 : Studies on the blood and bone marrow picture of the atomic bomb sufferers in Nagasaki, especially in Nishiyama area. Report to the Special Research Committee on the Atomic Bomb Disasters.

41) Kikuchi, T., G. Wakisaka, T. Setsuda, S. Anzai, T. Oga, T. Hiraoka, K. Murata, S. Itoi, T. Umeda, J. Okamoto, O. Hama, T. Murakami, T. Sawada, R. Ighigami, Y. Tajima, and S. Akiyama, 1946 : Hematological examination of the atomic bcmb sufferers in Hiroshima City one year after the bombing. Report to the Special Research Committee on the Atomic Bomb Disasters.

42) Snell, F. M., J. V. Neel, and K. Ishibashi, 1949 : Hematologic studies in Hiroshima and a control city two vears after the atomic bombing. Arch. Int. Med., 84, 569-604.

43) Kikuchi, T., G. Wakisaka, T. Yoda, S. Note, H. Yamada, and K. Miki, 1947 : Clinical observation of the atomic bomb sufferers in Nagasaki City one year and four months after the bombing. Report to the Special Research Committee on the Atomic Bomb Disasters.

44) Kikuchi T., G. Wakisaka, T. Setsuda, T. Yokoyama, B. Uba, M. Nishikawa, J. Tanaka, Y. Yamasoba, and S. Akiyama, 1947 : Hematological examination of the atomic bomb sufferers in Hiroshima City two years after the bcmbing. Report to the Special Research Committee on the Atomic Bomb Disasters.

45) March, H. C., 1944 : Leukemia in radiologists. Radiology, 43, 275. (Ref. in Am. J. Roentgen. \& Rad. Ther., 55, 790, 1946).

46) Henshaw, P. S. 1944 : Leukemia in mice following exposure to X-rays. Radiology, 43, 279. (Ref. in Am. J. Roentgen. \& Rad. Ther., 55, 789, 1946).

47) Lorenz, E., W. E. Heston, A. B. Eshenbrenner, and M. K. Deringer, 1947 : Biological studies in the tolerance range. Radiology, 49, 274-285.

48) Hempelmann, L. H., H. Lisco, and J. G. Hoffman, 1952 : The acute radiation syndrome. A study of nine cases and a review of the problem. Ann. Int. Med., 36, 279-510.

49) Watanabe, S., and T. Yamawaki, 1952 : Chronic radiation injuries caused by the atomic tomb. Read before the Fourteenth General Meeting of the Japanese Society of Hematology. 